\title{
The equatorial ligand effect on the properties and reactivity of iron(V)oxo intermediates
}

DOI:

10.1002/chem.201900708

Document Version

Accepted author manuscript

Link to publication record in Manchester Research Explorer

\section{Citation for published version (APA):}

De Visser, S., Pattanayak, S., Cantu Reinhard, F., Rana, A., \& Gupta, S. S. (2019). The equatorial ligand effect on the properties and reactivity of iron(V)oxo intermediates. Chemistry - A European Journal.

https://doi.org/10.1002/chem.201900708

\section{Published in:}

Chemistry - A European Journal

\section{Citing this paper}

Please note that where the full-text provided on Manchester Research Explorer is the Author Accepted Manuscript or Proof version this may differ from the final Published version. If citing, it is advised that you check and use the publisher's definitive version.

\section{General rights}

Copyright and moral rights for the publications made accessible in the Research Explorer are retained by the authors and/or other copyright owners and it is a condition of accessing publications that users recognise and abide by the legal requirements associated with these rights.

\section{Takedown policy}

If you believe that this document breaches copyright please refer to the University of Manchester's Takedown Procedures [http://man.ac.uk/04Y6Bo] or contact uml.scholarlycommunications@manchester.ac.uk providing relevant details, so we can investigate your claim.

\section{OPEN ACCESS}




\title{
The equatorial ligand effect on the properties and reactivity of iron(V)-oxo intermediates
}

\author{
Santanu Pattanayak, ${ }^{[\mathrm{a}]}$ Fabián G. Cantú Reinhard ${ }^{[\mathrm{b}]}$ Atanu Rana,${ }^{[\mathrm{c}]}$ Sayam Sen Gupta, ${ }^{[\mathrm{[a]}]}$ and Sam P. \\ de Visser ${ }^{*[b]}$
}

\begin{abstract}
High-valent metal-oxo oxidants are common catalytic cycle intermediates in enzymes and known to be highly reactive. To understand what features of these oxidants affect their reactivity, we synthesized and characterized a series of novel biomimetic iron( $(\mathrm{V})$ oxo oxidants with periphery substituted biuret-modified tetraamidomacrocyclic ligand. We find major shifts in the UV-Vis absorption as a result of replacing a group in the equatorial plane of the iron(V)-oxo species. Further characterization using EPR, ESI-MS and resonance Raman spectroscopy predict structural differences and the electronic configuration of these complexes. A systematic reactivity study with a range of substrates was performed and shows that the reactions are affected by electron-withdrawing substituents in the equatorial ligand, which enhances the reaction rate by almost 16 orders of magnitude. As such, the long-range electrostatic perturbations have a major influence on the rate constant. Finally, computational studies identify the various electronic contributions to the rate determining reaction step and explain how the equatorial ligand periphery affects the properties of the oxidant.
\end{abstract}

\section{Introduction}

The selective conversion of relatively inert aliphatic $\mathrm{C}-\mathrm{H}$ bonds to the corresponding alcohol is important in biology as well as industrial catalysis and its applications have been studied for many years. ${ }^{[1]}$ Nature utilizes high-valent iron(IV)-oxo intermediates for these substrate hydroxylation reactions, which are the active species in the catalytic cycles of both heme and nonheme iron enzymes. ${ }^{[2,3]}$ In particular, the iron(IV)-oxo heme cation radical (Compound I, Cpdl) species of heme monoxygenases such as the cytochromes P450 is known to be a good oxidant. As such it is responsible for drug metabolizing reactions in the liver as well as hormone biosynthesis reactions. Cpdl has been characterized with UV-Vis, electron paramagnetic resonance and Mössbauer spectroscopy, while subsequent reactivity studies assigned it as the active species in the catalytic cycle of P450 enzymes. ${ }^{[4]}$ Combined experimental

[a] Mr S. Pattanayak, Dr S. S. Gupta Department of Chemical Sciences,

Indian Institute of Science Education and Research (IISER

Kolkata, Mohanpur 741246, India

E-mail: sayam.sengupta@iiserkol.ac.in

[b] Dr F.G. Cantú Reinhard, Dr S.P. de Visser

Manchester Institute of Biotechnology and School of Chemical

Engineering and Analytical Science,

The University of Manchester

131 Princess Street, Manchester M1 7DN, United Kingdom

E-mail: sam.devisser@manchester.ac.uk

[c] Dr A. Rana

Indian Association for the Cultivation of Sciences,

2A Raja S. C. Mullick Road, Kolkata 700032, India

Supporting information for this article is given via a link at the end of the document. and computational studies identified Cpdl as having a doublet spin ground state with three unpaired electrons: two in $\pi^{\star} \mathrm{FeO}$ orbitals and one on the heme in an orbital labelled $\mathrm{a}_{2 u} \cdot{ }^{[4,5]}$ This unusual electronic state leads to the so-called two-statereactivity patterns of Cpdl whereby multiple electronic and spin states can be accessed during the reaction mechanism, which also affects product distributions. By contrast, nonheme iron(IV)oxo intermediates lack the ligand radical of the heme system and usually have a quintet spin ground state and typically react via single-state-reactivity. ${ }^{[6]}$

To gain insight into the structure and reactivity of enzymatic intermediates and understand the effect of ligand features and their direct environment a large number of biomimetic models have been generated and investigated. ${ }^{[7]}$ These studies have given insight into the effect of the ligand coordination, ${ }^{[8]}$ spinstate ordering, ${ }^{\left[{ }^{[9]}\right.}$ and hydrogen bonding interactions ${ }^{[10]}$ that affect the properties and reactivity of the oxidants. In particular, it was found that nonheme iron(IV)-oxo is more reactive in the quintet spin state than in the triplet spin state probably due to exchange stabilization of the product structures. ${ }^{[11]}$ Furthermore, pentacoordinated (trigonal bipyramidal) iron(IV)-oxo complexes were found to stabilize high-spin states and hence were predicted to be better catalysts of oxygen atom transfer reactions. ${ }^{[12]}$

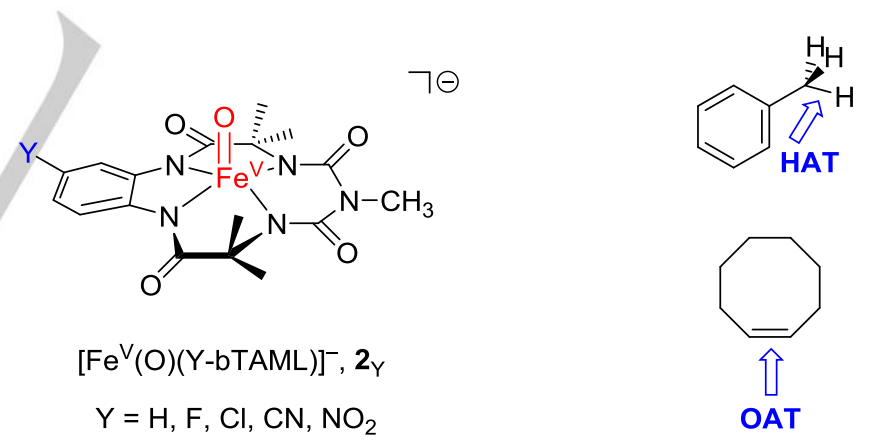

Scheme 1. Oxidants and reactions investigated in this work.

Despite the fact that iron(IV)-oxo intermediates appear relatively frequent in enzymatic catalytic cycles in biology, higher oxidation state iron complexes are rare. In particular, there are few enzymes in Nature that generate an iron(V)-oxo species in their catalytic cycle, including Rieske and naphalene dioxygenases. ${ }^{[13]}$ Despite this, several synthetic nonheme iron(V)-oxo species were trapped and characterized in recent years. ${ }^{[14]}$ Thus, some of us reported the synthesis and characterization of $\left[\mathrm{Fe}^{\mathrm{V}}(\mathrm{O})(\mathrm{bTAML})\right]^{-}, \quad \mathrm{bTAML} \quad$ = biuret-modified tetraamidomacrocyclic ligand, ${ }^{[15]}$ Scheme 1 . This complex was found to be stable at room temperature and reacted with substrates with relatively strong aliphatic $\mathrm{C}-\mathrm{H}$ bonds. Further reactivity studies alongside computational modelling showed that the lowest unoccupied molecular orbital (LUMO) constitutes 
contributions from the axial and equatorial ligands. ${ }^{[16]}$ As such, we expect the addition of electron-withdrawing groups to the TAML framework to drastically affect the LUMO and hence the reduction potential as well as the $\mathrm{pK}_{\mathrm{a}}$ of the oxidant. This in its turn may result in improved oxygen atom transfer to substrates. As such, we decided to synthesize a set of novel $\left[\mathrm{Fe}^{\mathrm{V}}(\mathrm{O})(\mathrm{Y}\right.$ bTAML)] $]^{-}$complexes (2Y) with $\mathrm{Y}=\mathrm{H}, \mathrm{F}, \mathrm{Cl}, \mathrm{CN}$ and $\mathrm{NO}_{2}$ with electron-withdrawing substituents attached to the periphery of the TAML ligand and do a systematic reactivity study with model substrates. These equatorial ligand substituted iron(V)-oxo complexes were subjected to a reaction with aliphatic substrates and olefins, Scheme 1. Thus, we studied hydrogen atom transfer (HAT) and oxygen atom transfer (OAT) to the double bond of cyclooctene. Our studies show that small perturbations in the equatorial ligand frame of the oxidant can have a significant effect on the oxidative properties of an iron(V)-oxo species and affect orbital interactions and enhance their reactivities with substrates. Therefore, small perturbations in the ligand framework affect the coordination environment of the metal center and these subtle changes are affecting reactivity patterns.

\section{Results}

Synthesis and characterization of iron(V)-oxo species. The iron(III)-chloro complexes $\left[\mathrm{Fe}^{\text {III }}(\mathrm{Cl})(\mathrm{Y}-\mathrm{bTAML})\right]^{2-} \quad\left(\mathbf{1}_{\mathrm{Y}}\right)$ were synthesized as described in the Experimental Section and characterized by single crystal X-ray diffraction (XRD), high resolution mass spectrometry (HRMS), UV-Vis spectroscopy, electrochemistry and electron paramagnetic resonance (EPR) spectrometry. ${ }^{[17]}$ Addition of equimolar amounts of aqueous sodium hypochlorite to a solution containing $1_{\mathrm{Y}}(\mathrm{Y}=\mathrm{H}, \mathrm{F}, \mathrm{Cl}, \mathrm{CN}$, $\mathrm{NO}_{2}$ ) resulted in a change of color to dark violet (due to a broad absorption of around $890-950 \mathrm{~nm}$ ). Subsequently, the species decays into an amber colored species for $\mathrm{Y}=\mathrm{NO}_{2}$ and a green colored species for all other oxidants. The UV-Vis spectral changes implicate that after addition of an equimolar amount of oxidant, it first forms an EPR silent species that most likely represents the $\mu$-oxodiiron(IV) species similar to the unsubstituted oxidant. ${ }^{[15]}$ The green species has characteristic peaks in the UV-Vis spectrum at 445 and $610 \mathrm{~nm}$ and was previously characterized as an iron(V)-oxo species. The electron -withdrawing effect of the substituents on the bTAML ligand show considerable effects on the UV-Vis spectra, namely when the electron donating ability of the substituent is enhanced, i.e. from $\mathrm{NO}_{2}$ to $\mathrm{H}$, the absorption band at $600 \mathrm{~nm}$ is red-shifted, Figure 1).

Subsequently, we characterized the complexes $2 \mathrm{y}, \mathrm{Y}=\mathrm{H}, \mathrm{F}, \mathrm{Cl}$, $\mathrm{CN}$ and $\mathrm{NO}_{2}$ with EPR spectrometry and mass spectrometry (Supporting information, Figures S2 - S4). Figure 2 displays the obtained EPR spectra of structures $\mathbf{2}_{\mathrm{F}}, \mathbf{2}_{\mathrm{Cl}}$ and $\mathbf{2}_{\mathrm{CN}}$, while the analogous spectra of $\mathbf{2}_{\mathrm{H}}$ and $\mathbf{2}_{\mathrm{NO}}$ were reported elsewhere. ${ }^{[15,18]}$ All substituted iron(V)-oxo complexes give $g_{\mathrm{x}}, g_{\mathrm{y}}$ and $g_{\mathrm{z}}$ tensor values in the EPR spectra similar to those observed for the unsubstituted system with an $S=1 / 2$ spin state. The iron-oxo species was further characterized using Resonance Raman spectroscopy that identified Fe-O stretch vibrations $\left(v_{\mathrm{Fe}=\mathrm{O}}\right)$ for complex $2_{\mathrm{H}}\left(862 \mathrm{~cm}^{-1}\right)$ and $2_{\mathrm{NO} 2}\left(866 \mathrm{~cm}^{-1}\right)$, which showed a 38 $\mathrm{cm}^{-1}$ downshift upon replacement of ${ }^{16} \mathrm{O}$ by ${ }^{18} \mathrm{O} .{ }^{[16,18]}$ Therefore, the replacement of an equatorial substituent on the periphery of the TAML ligand does not affect the electronic ground state of the iron(V)-oxo species and it remains in a doublet spin ground state. However, the equatorial ligand does affect the high-lying occupied and low-lying virtual orbitals as is seen from the dramatic shifts in the UV-Vis spectra for the five complexes. Whether these changes will affect the reactivity patterns is discussed in the next section.

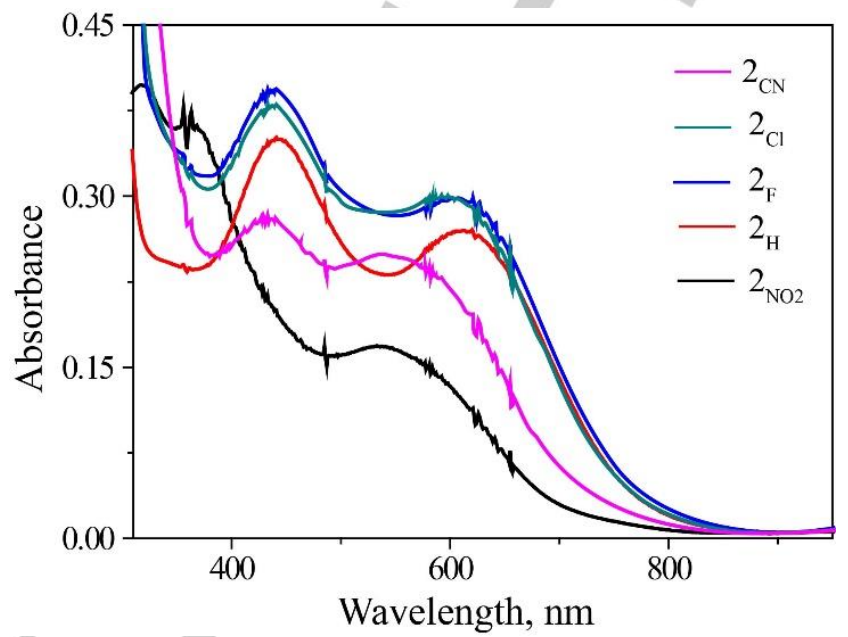

Figure 1. UV-Vis absorption spectra of iron(V)-oxo species $2 \mathrm{Y}\left[\mathrm{Y}=\mathrm{H}\left(1 \times 10^{-4}\right.\right.$ $\left.\mathrm{M}), \mathrm{F}\left(1 \times 10^{-4} \mathrm{M}\right), \mathrm{Cl}\left(9.34 \times 10^{-5} \mathrm{M}\right), \mathrm{CN}\left(4.6 \times 10^{-5} \mathrm{M}\right), \mathrm{NO}_{2}\left(4.6 \times 10^{-5} \mathrm{M}\right)\right]$ synthesized by oxidizing their iron(III) analogue with sodium hypochlorite in acetonitrile at room temperature.

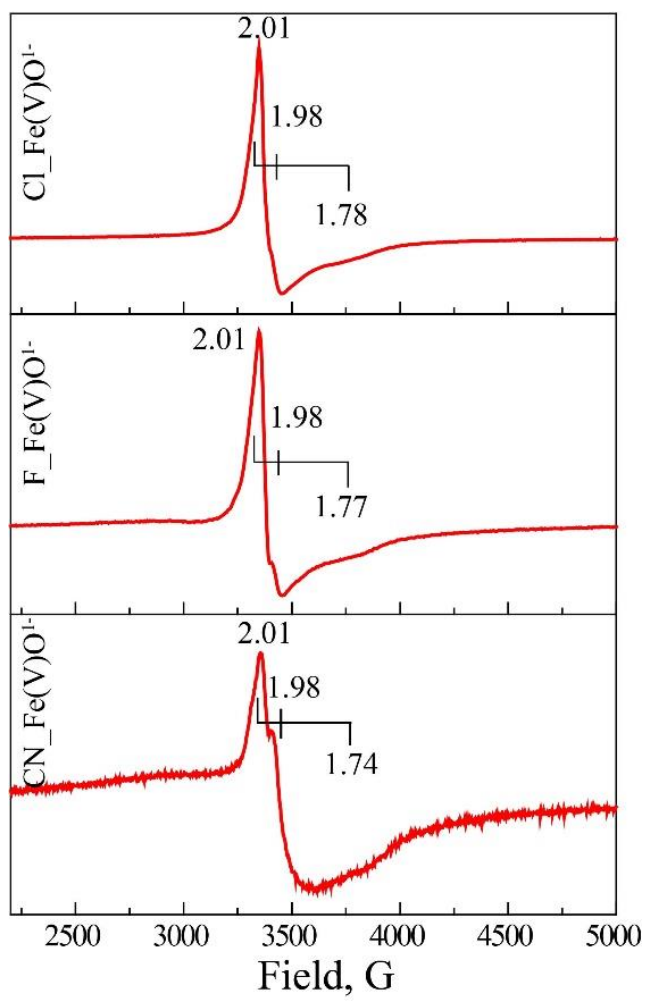

Figure 2. X-band EPR spectra of $\mathbf{2}_{\mathrm{F}}, \mathbf{2}_{\mathrm{Cl}}$ and $\mathbf{2}_{\mathrm{CN}}$ recorded at $\mathrm{T}=90 \mathrm{~K}$ Samples were prepared by adding 1.2 equiv of aqueous sodium hypochlorite solution to a $1 \mathrm{mM}$ solution of $\left[(\mathrm{Y}-\mathrm{bTAML}) \mathrm{Fe}^{\prime \prime \prime}(\mathrm{Cl})\right]$ in acetonitrile at $0^{\circ} \mathrm{C}$. 
Reactivity of iron(V)-oxo species. To understand the electronic effects on the reactivity of the iron(V)-oxo complexes $2_{\mathrm{Y}}\left(\mathrm{Y}=\mathrm{H}, \mathrm{F}, \mathrm{Cl}, \mathrm{CN}, \mathrm{NO}_{2}\right)$, we tested their substrate activation mechanisms with typical substrates, namely toluene and cyclooctene. Thus, we studied hydrogen atom transfer (HAT) from the aliphatic group of toluene and oxygen atom transfer (OAT) to cyclooctene by the iron(V)-oxo species.

Let us first discuss the hydrogen atom abstraction of toluene by the various oxidants in detail. Addition of substrate to a reaction mixture leads to a change in absorption spectra of 2 . The reaction of $2 y$ with toluene and cis-cyclooctene under argon atmosphere was monitored at $\sim 395 \mathrm{~nm}$ (depending upon the catalyst), which is the isosbestic point of the $\mathrm{Fe}^{\mathrm{III}}$ and $\mathrm{Fe}^{\mathrm{IV}}-\mathrm{O}$ $\mathrm{Fe}^{\mathrm{IV}}$ end-product formed during the reaction. In short, the HAT and OAT reactions with various substituted $2 Y$ give oxygenated product and regenerate the starting $\mathrm{Fe}^{\mathrm{III}}$ complexes. Fast comproportionation of $\mathrm{Fe}$ (III) with $\mathbf{2}_{\mathrm{Y}}$ leads to the formation of $\left[\mathrm{Fe}^{\mathrm{IV}}-\mathrm{O}-\mathrm{Fe}^{\mathrm{IV}}\right]^{2-}$. As soon as $\left[\mathrm{Fe}^{\mathrm{IV}}-\mathrm{O}-\mathrm{Fe}^{\mathrm{IV}}\right]^{2-}$ forms, the kinetics traces display an isosbestic point at $\sim 395 \mathrm{~nm}$. Since [Fe ${ }^{\mathrm{IV}}-\mathrm{O}$ $\left.\mathrm{Fe}^{\mathrm{IV}}\right]^{2-}$ has absorbance maxima at 380,613 , and $850 \mathrm{~nm}$, studying the kinetics of these complexes is complicated. Therefore, measuring change in absorption at $380 \mathrm{~nm}$, i.e. the $\mathrm{Fe}^{\text {III }}$ formation, or at $613 \mathrm{~nm}$, i.e. the decay of the $\left[\mathrm{Fe}^{\mathrm{V}}(\mathrm{O})(\mathrm{bTAML})\right]^{-}$complex will results into incorrect rate values. Due to these overlapping absorption patterns, the kinetics for the oxidation of substrates was measured by monitoring the absorbance change of $2 Y$ at the isosbestic point of [ $\left[\mathrm{F}^{\mathrm{IV}}-\mathrm{O}\right.$ $\left.\mathrm{Fe}^{\mathrm{IV}}\right]^{2-}$ and $\mathrm{Fe}^{\mathrm{III}}$ at room temperature under argon atmosphere. The changes in absorption at the isosbestic point were then plotted as a function of time and fitted with the nonlinear curve fitting equation $\left[A_{\mathrm{t}}=A_{\alpha}-\left(A_{\alpha}-A_{0}\right) \mathrm{e}^{(- \text {kobs t })}\right]$ which enabled us to determine the pseudo first-order rate constant $\left(k_{\mathrm{obs}}\right)$ of the reaction (Supporting Information, Figures S5 - S8). Subsequently, we measured the $k_{0 b s}$ at various substrate concentrations, from which we estimated the second-order rate constant $k_{2}$ for the various reactions (Supporting Information, Table S2, Figures S5 - S8). Hydrogen atom abstraction rate constants from toluene by $2 y$ were measured under single turnover number (TON) conditions under an argon atmosphere following methods published by us previously. ${ }^{[15]}$ The yields of benzaldehyde were measured to be less than $50 \%$ for reaction of toluene with 2 y (Supporting Information, Table S2).

The second-order rate constants for HAT from toluene by $2 y$ increase dramatically when a more electron-withdrawing group is added to the equatorial ligand. In particular, a rate enhancement of a factor of 15.7 is obtained between the oxidants with $\mathrm{Y}=\mathrm{H}$ to $\mathrm{Y}=\mathrm{NO}_{2}$. To understand the substituent effect on the reaction, we plot in Figure 3 the natural logarithm of the second-order rate constant for the reaction of toluene with $2 Y$ $\left(\mathrm{Y}=\mathrm{H}, \mathrm{F}, \mathrm{Cl}, \mathrm{CN}\right.$ and $\mathrm{NO}_{2}$ ) with respect to that of $\mathbf{2}_{\mathrm{H}}$ as a function of the sum of the Hammett parameters $\sigma_{\mathrm{p}}$ and $\sigma_{\mathrm{m}}{ }^{\left[{ }^{[19]}\right.}$ An attempt to correlate the experimental thermodynamic and kinetics parameters of hydrogen atom abstraction from toluene with either the meta $\left(\sigma_{m}\right)$ or para $\left(\sigma_{p}\right)$ Hammett constant value leads near-linear correlations although the regression values are relatively low (Supporting Information Figure S9). Thus, the substituents are para toward one of the nitrogen ligands of the metal but meta toward another one; therefore, we investigated the trends of the sum of the two values (considering equal contribution of both positions), i.e. $\sigma^{*}=\sigma_{\mathrm{m}}+\sigma_{\mathrm{p}}$. Indeed, a considerably improved correlation for the Hammett plot is found
(Figure 3). As can be seen from Figure 3a the natural logarithm of the rate constant for HAT from toluene by $2 Y$ increases linearly with the increased electron-withdrawing ability of the substituent. These results show that the reaction proceeds through a common mechanism for all oxidants.
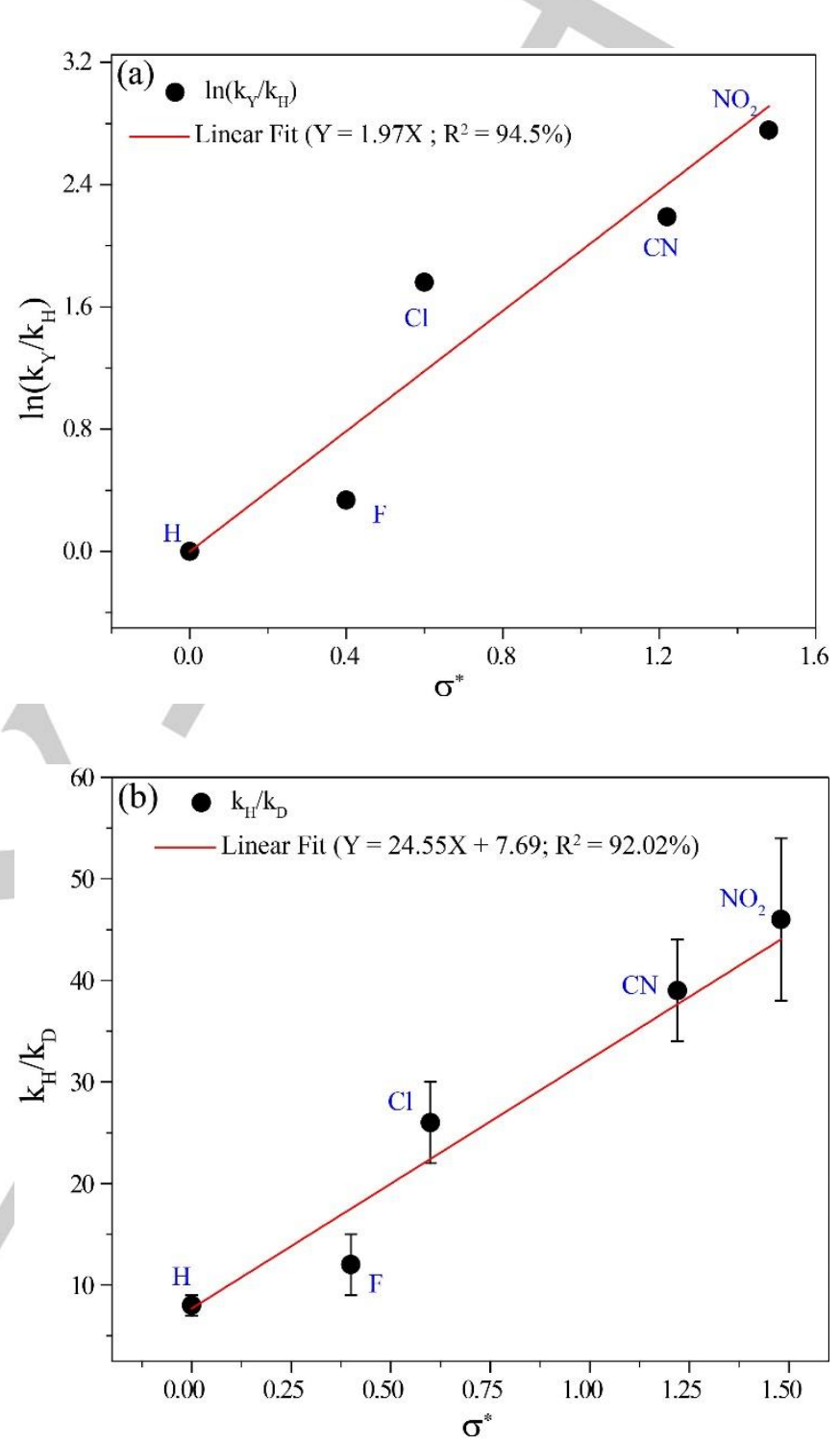

Figure 3. (a) Plot of the natural logarithm of the second-order rate constants for HAT from toluene by $2_{\gamma}$ as a function of the sum of the $\sigma_{m}$ and $\sigma_{p}$ Hammett parameters of the substituents. (b) KIE values as a function of Hammett parameter of the substituents.

Hydrogen atom abstraction by $2_{Y}$ was investigated with toluene and toluene- $\left[\mathrm{D}_{8}\right]$, which enabled us to measure the kinetic isotope effect $\left(\mathrm{KIE}=k_{\mathrm{H}} / k_{\mathrm{D}}\right)$ of the reaction. The non-classical $\mathrm{KIE}$ values for the reaction of $2 y$ with toluene/toluene-[ $\left.\mathrm{D}_{8}\right]$ and their deviations from unity indicate that the rate-determining step is the hydrogen atom abstraction. This matches the result obtained for the unsubstituted system reported before. ${ }^{[16,20]}$ We plot the ratio of $k_{H} / k_{D}$ as a function of the sum of the Hammett parameters $\sigma_{\mathrm{m}}$ and $\sigma_{\mathrm{p}}$ in Figure $3 \mathrm{~b}$. Also here a linear correlation is observed, which implies that the hydrogen atom abstraction barriers are narrower and sharper for systems with electron- 
withdrawing substituents leading to a larger effect of tunneling and an enhanced KIE value.

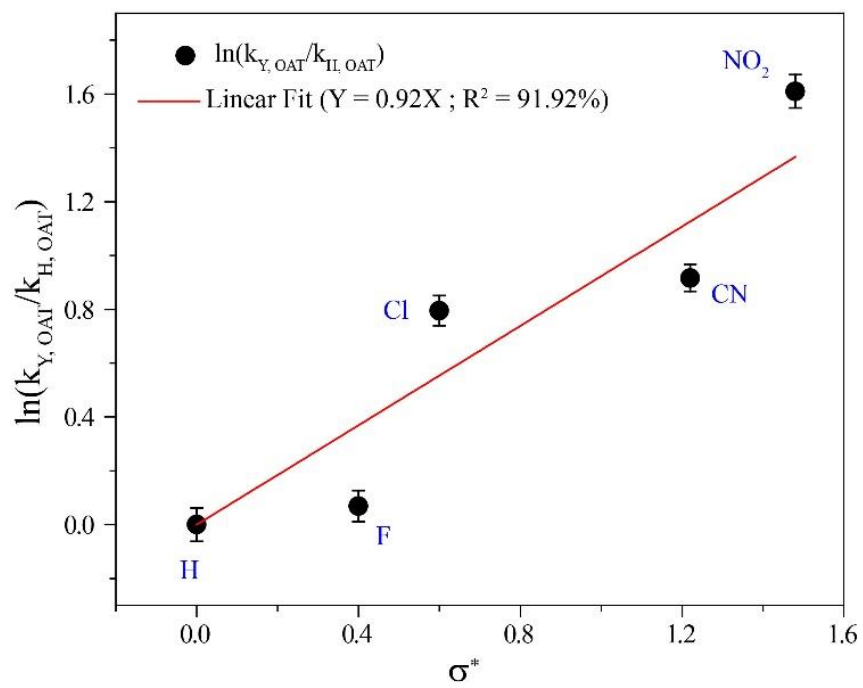

Figure 4. Plot of the natural logarithm of the second-order rate constants for OAT to cyclooctene by $2 \gamma$ as a function of the sum of the $\sigma_{m}$ and $\sigma_{p}$ Hammett parameters of the substituents.

Subsequently, we investigated oxygen atom transfer (OAT) of complexes $2 \mathrm{Y}\left(\mathrm{Y}=\mathrm{H}, \mathrm{F}, \mathrm{Cl}, \mathrm{CN}\right.$ and $\left.\mathrm{NO}_{2}\right)$ to cyclooctene to form the corresponding epoxide. The aim of these studies was to understand the effect of electron-withdrawing substituents in the equatorial plane on the reactivity of the iron(V)-oxo complex. The pseudo first-order rate constants of OAT from $2 \mathrm{Y}$ to cyclooctene were determined from the change in absorption of $\mathbf{2}_{\mathrm{Y}}$ at the isosbestic point of $\left[\mathrm{Fe}^{\mathrm{IV}}-\mathrm{O}-\mathrm{Fe}^{\mathrm{IV}}\right]^{2-}$ and $\mathrm{Fe}^{\mathrm{III}}$ as a function of time. Plots of these pseudo first-order rate constants as a function of the substrate concentration enabled us to determine second-order rate constants $k_{2}$ (Supporting Information Figures S10 - S13, Table S3). ${ }^{[21]}$ The yield of cycloocteneoxide (cis and trans) was found to be $\sim 70 \%$ under argon atmosphere at room temperature (Supporting Information Table S3). As shown in Figure 4 the natural logarithm of the second-order rate constant for OAT is linearly related to the sum of the $\sigma_{\mathrm{m}}$ and $\sigma_{\mathrm{p}}$ Hammett parameters. The slope of the curve is considerably smaller than that seen for hydrogen atom abstraction and indeed the rate enhanced by only a factor of 5 between the oxidants with $\mathrm{Y}=\mathrm{H}$ and $\mathrm{Y}=\mathrm{NO}_{2}$.

The trends shown in Figure $3 \mathrm{a}$ and Figure 4 for HAT and OAT by $2_{Y}\left(\mathrm{Y}=\mathrm{H}, \mathrm{F}, \mathrm{Cl}, \mathrm{CN}, \mathrm{NO}_{2}\right)$ implicate that in both cases the equatorial ligand affects the rate constant of the reaction, but to a different extend. Previously, it was shown that trends in hydrogen atom abstraction for a series of analogous oxidants can be correlated to either the strength of the $\mathrm{C}-\mathrm{H}$ bond of the substrate that is broken, ${ }^{[21]}$ or the strength of the $\mathrm{O}-\mathrm{H}$ bond of the iron-hydroxo complex that is formed. ${ }^{[23]}$ Often, therefore, these correlations are given in terms of the bond dissociation energy (BDE) of either the $\mathrm{C}-\mathrm{H}$ or $\mathrm{O}-\mathrm{H}$ bonds broken or formed. Thermodynamically, the $\mathrm{BDE}_{\mathrm{OH}}$ value can be split into individual components for the electron affinity of the iron(V)-oxo species, i.e. its redox potential $\mathrm{E}_{2 \mathrm{Y}}^{\circ}$, the $\mathrm{pK}_{\mathrm{a}}$ value of the iron(IV)-hydroxo complex and the ionization energy of a hydrogen atom ( $\left.\mathrm{IE}_{\mathrm{H}}\right)$, Eq
1. ${ }^{[24]}$ The individual components $\mathrm{E}^{\circ}{ }_{2 \mathrm{Y}}$ and $\mathrm{pK}_{\mathrm{a}, \mathrm{FeOH}}$ were determined for all complexes (Supporting Information) and give $\mathrm{BDE}_{\mathrm{OH}}$ values that range from $98.6 \mathrm{kcal} \mathrm{mol}^{-1}$ for $\mathrm{Y}=\mathrm{H}$ to 102.0 $\mathrm{kcal} \mathrm{mol}{ }^{-1}$ for $\mathrm{Y}=\mathrm{NO}_{2}$. It was found that the main difference was due to changes in the reduction potential (by $5.3 \mathrm{kcal} \mathrm{mol}^{-1}$ ) and a smaller and inverse amount due to $\mathrm{pK}_{\mathrm{a}}$ changes (by $-1.3 \mathrm{kcal}$ $\mathrm{mol}^{-1}$ ).

$\mathrm{BDE}_{\mathrm{OH}}=23.06 \times \mathrm{E}^{\circ}{ }_{2 \mathrm{Y}}+1.37 \mathrm{pK}_{\mathrm{a}, \mathrm{FeOH}}+\mathrm{IE}_{\mathrm{H}}$

As during HAT an iron(IV)-hydroxo complex is formed, we decided to plot the natural logarithm of the second-order rate constant of the complexes against their $\mathrm{BDE}_{\mathrm{OH}}$ values (Figure $5 a)$. As can be seen there is indeed a nice linear correlation with $\mathrm{R}^{2}=0.95$, which implicates that the $\mathrm{BDE}_{\mathrm{OH}}$ is the major component that determines the hydrogen atom abstraction trend for this series and all complexes will react via the same electronic mechanism.
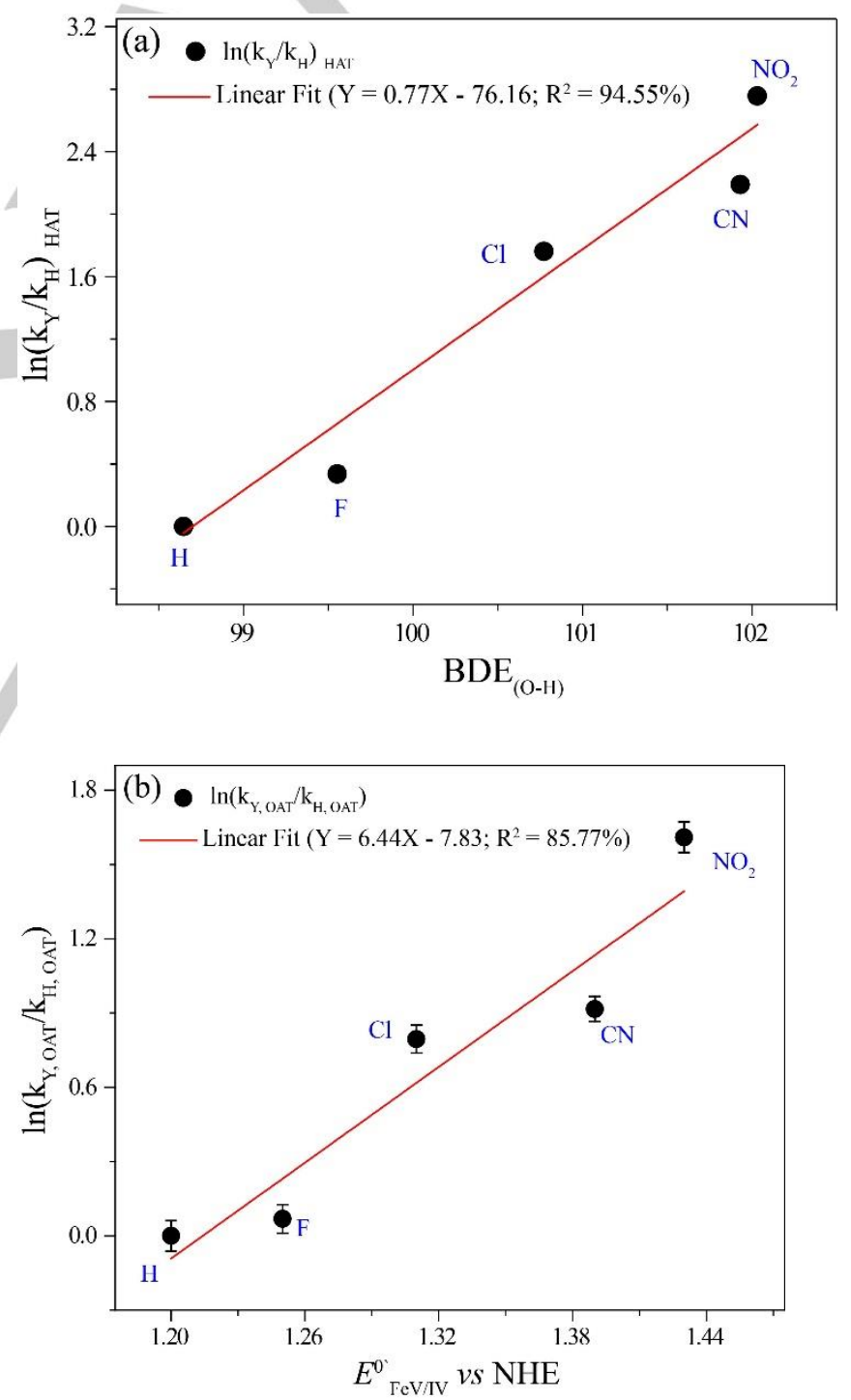

Figure 5. (a) Plot of the natural logarithm of the second-order rate constants for HAT from toluene by $2_{Y}$ as a function of the BDE $\mathrm{OH}_{\mathrm{OH}}$ of the iron(IV)-hydroxo complex. (b) Plot of the natural logarithm of the second-order rate constants for OAT to cyclooctene by $2 \mathrm{Y}$ as a function of the redox potential of the iron(V) complex. 
The OAT from oxidant to cyclooctene will start with a ratedetermining $\mathrm{C}-\mathrm{O}$ bond formation step generating a radical and hence should correlate with the redox potential of the iron $(\mathrm{V})$ oxo complex. As can be seen from Figure $5 b$ the trend between natural logarithm of the rate constant of OAT versus redox potential is reasonably linear, which implicates all reactions proceed through the same mechanism but that the ratedetermining step is affected by the equatorial ligand. Similarly as seen for the HAT reaction, the reactivity is affected by the amount of electrophilicity of the equatorial ligand system. Previously it was shown that the formation of a $\mathrm{C}-\mathrm{O}$ or $\mathrm{S}-\mathrm{O}$ bond can be approximated by the formation of an $\mathrm{O}-\mathrm{H}$ bond, hence correlations were seen between $\mathrm{BDE}_{\mathrm{OH}}$ and the free energy of activation for substrate epoxidation and sulfoxidation reactions. ${ }^{[25]}$

Computation. To understand the observed experimental trends and gain deeper insight into the electronic properties of this iron(V)-oxo complex and its reactivity patterns, we followed the studies up with a series of density functional theory calculations. We initially optimized the reactant complexes $2 \mathrm{Y}(\mathrm{Y}=\mathrm{H}, \mathrm{F}, \mathrm{Cl}$, $\mathrm{CN}, \mathrm{NO}_{2}$ ) and analyzed the geometry and electronic configuration of the structures. All species are in a doublet spin ground state in agreement with the EPR results reported above. The quartet spin states are higher in energy by $4.0(\mathrm{Y}=\mathrm{H})$ to 7.9
$\left(\mathrm{Y}=\mathrm{NO}_{2}\right) \mathrm{kcal} \mathrm{mol}^{-1}$ and stay higher in energy along the reaction mechanisms (Supporting Information, Table S5). The energy gap between the two spin states is increased when the geometry optimizations are done with the OPBE density functional method rather than B3LYP. Therefore, regardless of the computational method, the quartet spin state is well above the doublet spin state and will not play a role of importance here. Figure 6 gives optimized geometries of ${ }^{2} 2 \mathrm{Y}(\mathrm{Y}=\mathrm{H}, \mathrm{F}, \mathrm{Cl}, \mathrm{CN}$, $\mathrm{NO}_{2}$ ) as obtained with DFT. As can be seen the Fe-O distance in these complexes ranges from $1.590 \AA$ for ${ }^{2} \mathbf{2}_{\mathrm{H}}$ and drops gradually when an electron-withdrawing substituent is added to the ligand to a value of $1.579 \AA$ for ${ }^{2} \mathbf{2}_{\mathrm{CN}}$ and ${ }^{2} \mathbf{2}_{\mathrm{NO} 2}$. Although the changes in $\mathrm{Fe}-\mathrm{O}$ bond length upon equatorial ligand substitution are minor, the variation in $\mathrm{Fe}-\mathrm{O}$ stretch vibration $\left(v_{\mathrm{FeO}}\right)$ for these complexes is somewhat larger and increases from $964 \mathrm{~cm}^{-1}$ for ${ }^{2} \mathbf{2}_{\mathrm{H}}$ to $990 \mathrm{~cm}^{-1}$ for ${ }^{2} \mathbf{2}_{\mathrm{NO} 2}$. Clearly, the trend follows Badger's rule that correlates the inverse value of the $\mathrm{Fe}-\mathrm{O}$ stretch vibration with its bond length. ${ }^{[26]}$ These small changes could not be captured with resonance Raman measurements that gave no significant frequency changes upon equatorial ligand substitution. This may be due to the fact that the calculations were performed in the gas-phase, where these effects are stronger than in a polarized solvent with a cage of solvent molecules around our oxidant. (a)

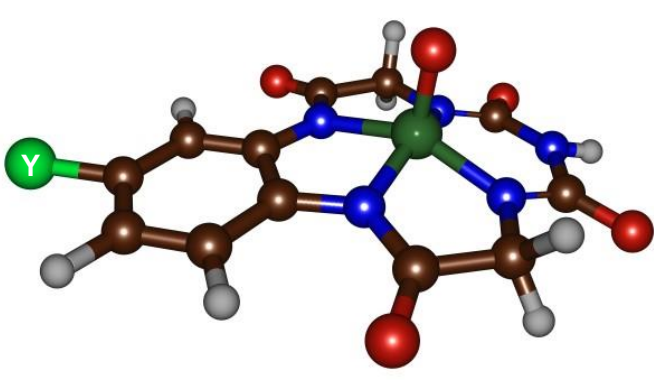

(b)
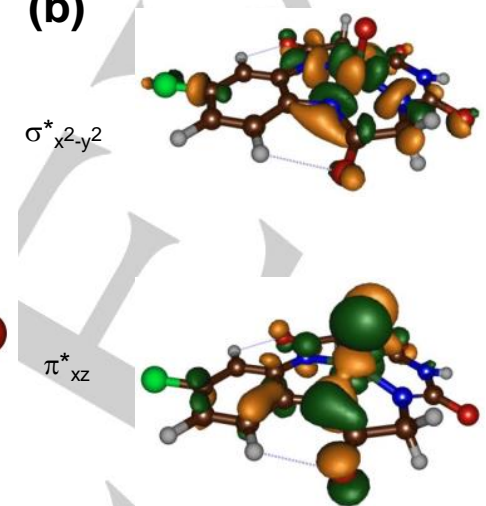

\begin{tabular}{|c|r|r|}
\hline $\mathrm{Y}$ & $\mathrm{r}(\mathrm{Fe}-\mathrm{O}), \mathbf{A}$ & $v_{\mathrm{FeO}, \mathrm{cm}^{-1}}$ \\
\hline $\mathrm{H}$ & 1.590 & 964 \\
\hline $\mathrm{F}$ & 1.583 & 970 \\
\hline $\mathrm{Cl}$ & 1.581 & 980 \\
\hline $\mathrm{CN}$ & 1.579 & 989 \\
\hline $\mathrm{NO}_{2}$ & 1.579 & 990 \\
\hline
\end{tabular}
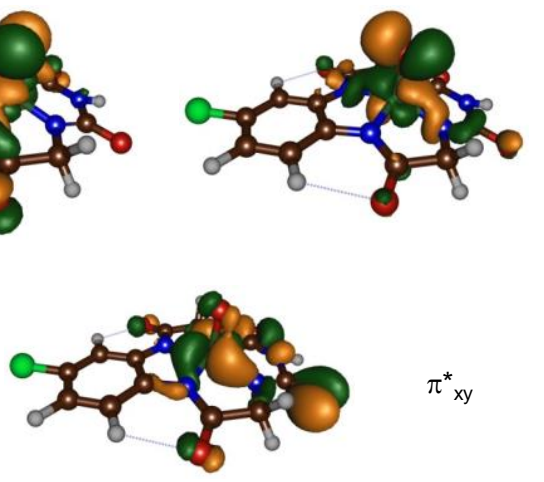

$\pi^{*}{ }_{x y}$

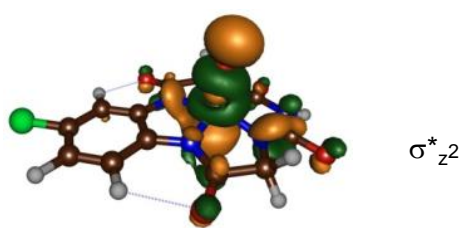

$\pi^{*} y z$

$$
\pi^{*} \mathrm{yz}
$$

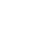
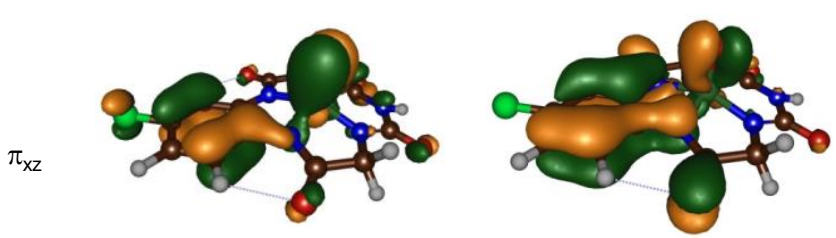

Figure 6. (a) UB3LYP/BS1 optimized doublet spin states of $2 \mathrm{Y}\left(\mathrm{Y}=\mathrm{H}, \mathrm{F}, \mathrm{Cl}, \mathrm{CN}, \mathrm{NO}_{2}\right)$ with bond lengths in angstroms and the $\mathrm{Fe}-\mathrm{O}$ strength vibration in $\mathrm{cm}^{-1}$. Data for $\mathrm{Y}=\mathrm{H}$ taken from Ref ${ }^{[15]}$ (b) High-lying occupied and low-lying virtual orbitals of ${ }^{2} \mathbf{2}_{\mathrm{H}}$ 
The high-lying occupied and low-lying virtual orbitals of ${ }^{2} \mathbf{2}_{\mathrm{H}}$ are shown on the right-hand-side of Figure 6 . These include the $\pi_{\mathrm{xz}}$ and $\pi_{\mathrm{yz}}$ molecular orbitals for the bonding interaction between the $3 d_{x z} / 3 d_{y z}$ on iron with the $2 p_{x} / 2 p_{y}$ on oxygen. Higher lying are the antibonding combination of those orbitals, i.e. $\pi_{x z}^{*}$ and $\pi_{y z}^{*}$. In the doublet spin state one of those $\left(\pi^{*} \times z\right)$ is singly occupied, while the other one is virtual. In between the $\pi_{x z}$ and $\pi_{x z}^{*}$ orbitals is a nonbonding orbital $\left(\pi^{*} x y\right)$ that is doubly occupied. Two virtual $\sigma^{*}$ orbitals are included in the Figure for the interactions of the metal with the equatorial ligand $\left(\sigma^{*} \times 2-y_{2}\right)$ and for interactions of the metal with the axial ligand $\left(\sigma^{*}{ }_{z 2}\right)$.

In the doublet spin state the orbital occupation is $\pi_{x z}{ }^{2} \pi_{y z}{ }^{2} \pi^{*}{ }_{x y}^{2}$ $\pi^{*}{ }^{1}{ }^{1}$ and hence the metal is formally in an iron $(V)$ oxidation state. The quartet spin state results in the excitation in the doublet spin state of an electron from the $\pi_{x y}^{*}$ orbital into $\pi_{y z}^{*}$, i.e. has configuration $\pi_{x z}{ }^{2} \pi_{y z}{ }^{2} \pi^{*}{ }_{x y}{ }^{1} \pi^{*}{ }_{x z}{ }^{1} \pi^{*}{ }^{*}{ }_{y z}$. Note that in the $\pi^{*}{ }_{x z}$ and $\pi^{*}{ }_{y z}$ orbitals the metal orbital mixes somewhat with a $2 p$ orbital on the ligand nitrogen atoms in the xy-plane. As such, electronwithdrawing substitutions on the ligand periphery may affect the energies of those orbitals and consequently the reduction potential of the complexes as well as their absorption transitions. The spin state ordering and relative energies matches previous calculations on iron(V)-oxo complexes well. ${ }^{[27]}$
Subsequently, we investigated toluene oxidation and cyclooctene epoxidation by $2_{\mathrm{Y}}\left(\mathrm{Y}=\mathrm{H}, \mathrm{F}, \mathrm{Cl}, \mathrm{CN}, \mathrm{NO}_{2}\right)$. Before we look into the trends of the rate-determining reaction steps, we describe the full mechanism for $\mathrm{Y}=\mathrm{Cl}$ as an example. Figure 7 shows the potential energy landscape for toluene hydroxylation by ${ }^{2,4} \mathbf{2}_{\mathrm{Cl}}$. The reaction is stepwise with an initial hydrogen atom abstraction via the hydrogen atom abstraction transition state $\left(\mathbf{T S}_{\mathrm{HA}}\right)$ to give the iron(IV)-hydroxo intermediate ( $\left.\mathbf{I}_{\mathrm{HA}}\right)$ and is followed by an $\mathrm{OH}$ rebound barrier via transition state $\mathbf{T S}_{\text {reb }}$ to give the alcohol product complexes $\left(\mathbf{P}_{\text {HAT }}\right)$. For all other oxidants the same mechanism is seen. In addition, for all systems the rate-determining step is the hydrogen atom abstraction, while the rebound barriers are well lower in energy. In the case of $\mathbf{2}_{\mathrm{Cl}}$, the doublet and quartet spin states are relatively close in energy at $\Delta \mathrm{E}+\mathrm{ZPE}$ level of theory, although the gap widens when solvent, entropic and thermal corrections are included.

The hydrogen atom abstraction is lowest in the doublet spin state with a barrier of $\triangle E+Z P E^{\ddagger}=10.8 \mathrm{kcal} \mathrm{mol}^{-1}$, whereas it is $14.6 \mathrm{kcal} \mathrm{mol}^{-1}$ in the quartet spin state. These barriers are low and are of similar value to those calculated for hydrogen atom abstraction from ethylbenzene by a cytochrome P450 Cpdl model. ${ }^{[28]}$ As such this iron(V)-oxo oxidant is a powerful oxidant that should be able to activate a range of substrates.

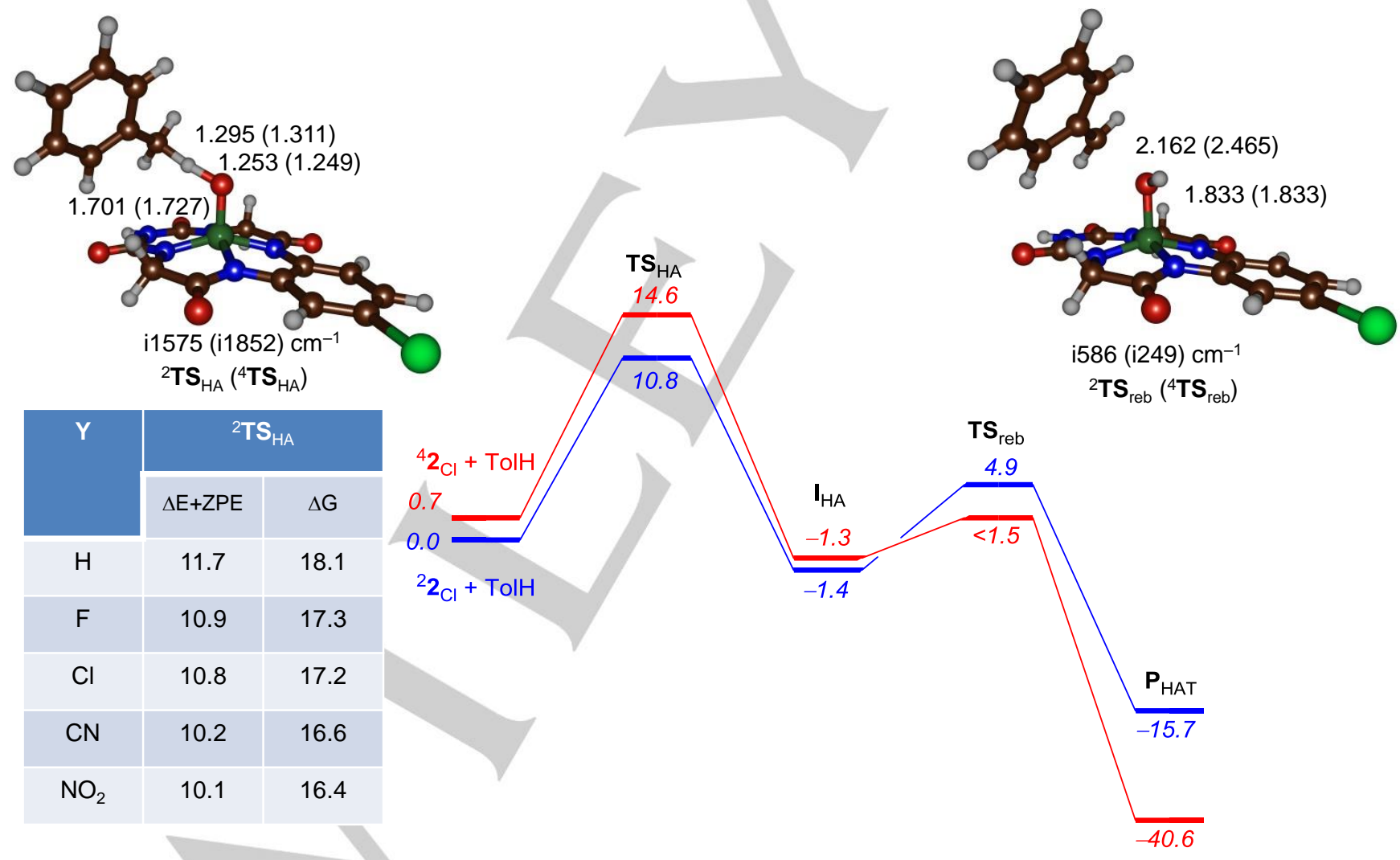

Figure 7. Potential energy landscape for toluene hydroxylation by ${ }^{2,4} \mathbf{2}_{\mathrm{Cl}}$ as calculated by B3LYP. Energies (in kcal mol ${ }^{-1}$ ) calculated with basis set BS2 and include zero-point and solvent corrections, whereas free energies $(\Delta G)$ use BS2 energies corrected for ZPE, solvent, thermal and entropic corrections. Optimized geometries of the transition states give bond lengths in angstroms and the imaginary frequency in wave numbers. 
In the doublet spin state, the hydrogen atom abstraction is accomplished through electron transfer into the virtual $\pi^{*}{ }_{y z}$ molecular orbital. Hence, the radical intermediate ( $\left.\mathbf{I}_{\mathrm{HA}}\right)$ can be described with the configuration $\pi_{\mathrm{xz}}{ }^{2} \pi_{\mathrm{yz}}{ }^{2} \pi^{*}{ }_{\mathrm{xy}}{ }^{2} \pi_{\mathrm{xz}}^{*}{ }^{1} \pi_{\mathrm{yz}}^{*}{ }^{1} \phi_{\mathrm{Tol}}{ }^{1}$, whereby the tolyl radical (in orbital $\phi_{\text {Tol }}$ ) has a down-spin electron and the two metal-type singly occupied molecular orbitals $\left(\pi^{*}\right.$ and $\left.\pi^{*}{ }_{y z}\right)$ are up-spin. Thus, the group spin densities on ${ }^{2} \mathbf{I}_{\mathrm{HA}}$ confirm this assignment. In the quartet spin state, by contrast, a down-spin electron is transferred from the $\mathrm{C}-\mathrm{H}$ bond of the substrate into the singly occupied $\pi_{x y}^{*}$ molecular orbital and leaves the tolyl radical in an up-spin conformation. Consequently, the doublet and quartet radical intermediates $\left({ }^{4,2} \mathbf{I}_{\mathrm{HA}}\right)$ have the same electronic configuration and indeed we find them as virtually degenerate.

Optimized geometries of ${ }^{2,4} \mathbf{T S}_{\mathrm{HA}, \mathrm{Cl}}$ are shown in Figure 7 . These structures are typical for toluene HAT transition states with the transferring hydrogen atom almost midway in between the donor and acceptor atoms. ${ }^{[29]}$ In particular, in the doublet spin state C$\mathrm{H}$ and $\mathrm{O}-\mathrm{H}$ distances of 1.295 and $1.253 \AA$ were found, respectively. Similar distances were obtained for the other oxidants (Supporting Information). Upon hydrogen atom abstraction the $\mathrm{Fe}-\mathrm{O}$ bond is elongated from $1.581 \AA$ in ${ }^{2} \mathbf{2}_{\mathrm{Cl}}$ to $1.701 \AA$ in ${ }^{2} \mathbf{T S}_{\mathrm{HA}, \mathrm{Cl}}$ and $1.773 \AA$ in ${ }^{2} \mathbf{I}_{\mathrm{HA}, \mathrm{Cl}}$. This change in $\mathrm{Fe}-\mathrm{O}$ bond length reflects the reduction of iron and the filling of the $\pi_{y z}^{*}$ molecular orbital with one electron, which is antibonding for the interaction.

In the next stage of the reaction the $\mathrm{OH}$ rebound to form alcohol products takes place. In the doublet spin state this step will be accomplished with electron transfer into the $\pi^{*}{ }_{x z}$ orbital to give a product with configuration $\pi_{x z}^{2} \pi_{y z}^{2} \pi_{x y}^{*}{ }^{2} \pi_{x z}^{*}{ }^{2} \pi_{y z}^{*}{ }^{1}$, whereas in the quartet spin state the $\sigma^{*}{ }_{z 2}$ will be populated with one electron and the following configuration is obtained: $\pi_{\mathrm{xz}}{ }^{2} \pi_{\mathrm{yz}}{ }^{2} \pi^{*}{ }_{\mathrm{xy}}{ }^{2} \pi^{*}{ }_{\mathrm{xz}}{ }^{1}$ $\pi_{\mathrm{yz}}^{*}{ }^{1} \sigma_{\mathrm{zz}}{ }^{1}$. In both cases, therefore, the product will be iron(III). The quartet spin state is considerably more stable due to exchange-enhanced spins. Moreover, due to the transfer of the oxygen atom, the $\sigma_{z 2}^{*}$ orbital converts back into an atomic nonbonding orbital $\left(3 \mathrm{~d}_{\mathrm{z} 2}\right)$ and is considerably stabilized in the product thereby making the quartet spin state the ground state.

The rebound transition states are shown in Figure 7 and have further elongated $\mathrm{Fe}-\mathrm{O}$ distances of $1.833 \AA$ in both spin state structures. The imaginary frequencies of the rebound transition states are considerably smaller than those found for hydrogen atom abstraction with values of i586 (i249) $\mathrm{cm}^{-1}$ for ${ }^{2} \mathbf{T S}_{\mathrm{reb}, \mathrm{Cl}}$ $\left({ }^{4} \mathbf{T S}_{\text {reb,Cl}}\right)$, respectively.

Subsequently, we investigated cyclooctene epoxidation by ${ }^{2,4} \mathbf{2}_{Y}$ $\left(\mathrm{Y}=\mathrm{H}, \mathrm{F}, \mathrm{Cl}, \mathrm{CN}, \mathrm{NO}_{2}\right.$ ). The potential energy landscape for $\mathrm{Y}=$ $\mathrm{Cl}$ is given in Figure 8 and similarly to the hydrogen atom abstraction it is stepwise via a radical intermediate. The same electron transfer mechanisms take place as on the toluene hydroxylation mechanism and the first $\mathrm{C}-\mathrm{O}$ bond formation barrier (transition state $\mathbf{T S}_{\mathrm{OAT}}$ ) is rate-determining. After the oxygen atom transfer transition state the system relaxes to a radical intermediate (IOAT) that via a ring-closure barrier $\left(\mathbf{T S}_{\mathrm{rC}}\right)$ leads to the epoxide product complexes $\left(\mathbf{P}_{\mathrm{OAT}}\right)$.

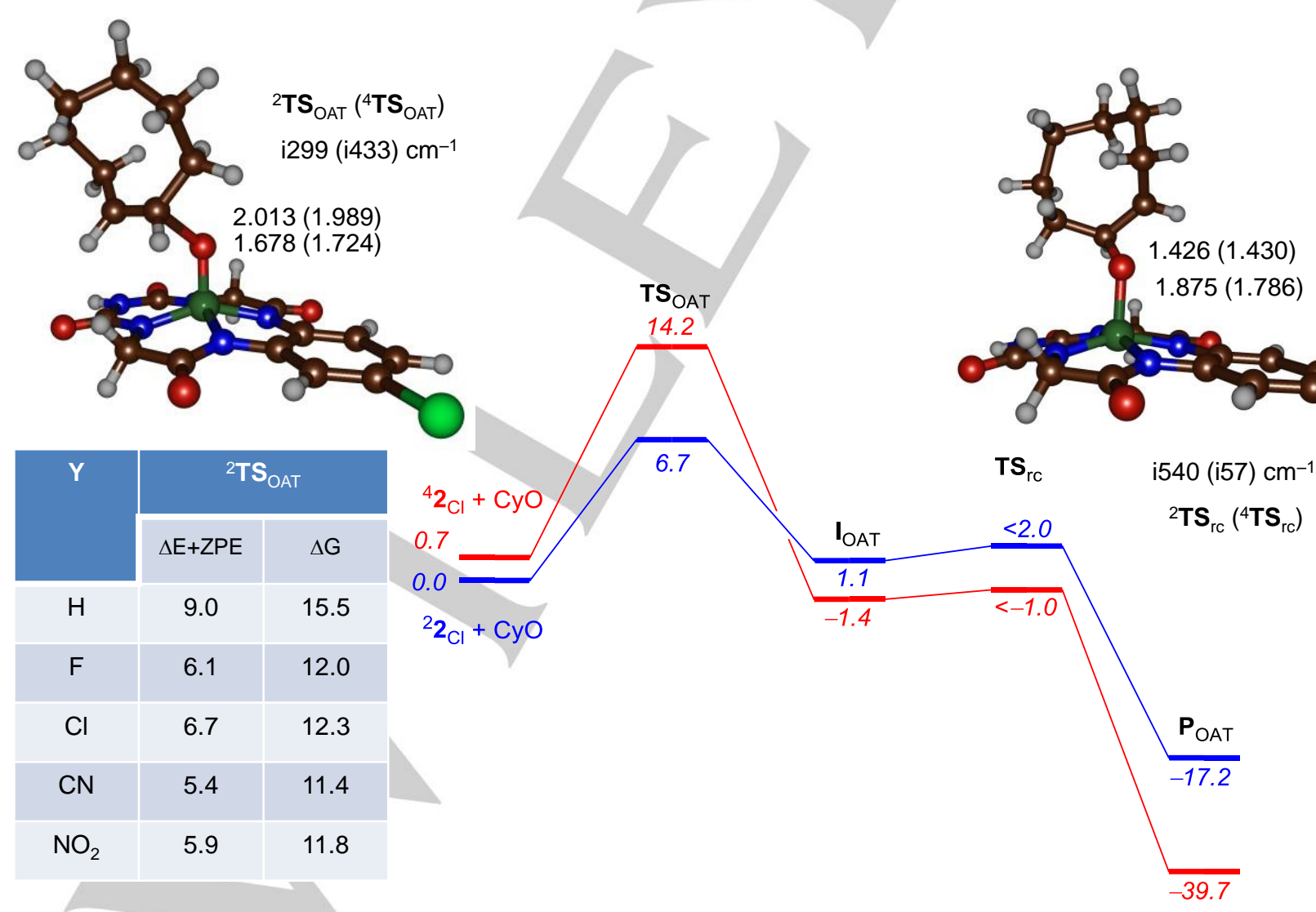

Figure 8. Potential energy landscape for cyclooctene (CyO) epoxidation by ${ }^{2,4} \mathbf{2}_{\mathrm{Cl}}$ as calculated by B3LYP. Energies (in kcal mol ${ }^{-1}$ ) calculated with basis set BS2 and include zero-point and solvent corrections. Optimized geometries of the transition states give bond lengths in angstroms and the imaginary frequency in wave numbers. 
In $\mathbf{T S}_{\mathrm{OAT}}$ the $\mathrm{Fe}-\mathrm{O}$ is elongated with respect to reactants and a single $\mathrm{C}-\mathrm{O}$ interaction is formed. The imaginary frequency for this process is low (i299 $\mathrm{cm}^{-1}$ for ${ }^{2} \mathbf{T} \mathbf{S}_{\mathrm{OAT}}$ ) as expected of substrate epoxidation barriers. ${ }^{[30]}$ Interestingly, the quartet spin drops already below the doublet spin in the radical intermediates although they both have the same electronic configuration. The ring-closure barrier is small and leads to products efficiently. Overall the electron transfer processes for substrate epoxidation are similar to those of the hydrogen atom abstraction processes described above and hence also a stepwise mechanism is found with a radical intermediate.

In general, the barriers for oxygen atom transfer drop with increasing electron-withdrawing substituent $Y$ as seen for the hydrogen atom abstraction barriers as well. Moreover, calculated free energies of activation are in good quantitative agreement with those observed experimentally. Therefore, the computational methods and procedures appear to be suitable for reproducing the experimental trends. To analyze the barriers further and find the origin of the substituent effects, we did a detailed thermochemical and valence bond analysis of the reaction mechanisms as described in the Discussion section.

\section{Discussion}

This work studies the equatorial ligand effect on the stability, spin-state ordering and reactivity of high-valent iron(V)-oxo complexes for the first time. Experimental rate constants show that a perturbation in the equatorial plane due to changes of ligand substitution leads to reactivity changes that correlate with the sum of the $\sigma_{\mathrm{m}}$ and $\sigma_{\mathrm{p}}$ Hammett parameters. In the following we will analyze the reactivity trends based on the sets of data on the hydrogen atom abstraction processes. Data with trends on oxygen atom transfer is given in the Supporting Information.

Using transition state theory, the experimental second-order rate constants were converted into a free energy of activation, which gave values ranging from $\Delta \mathrm{G}^{\ddagger}=19.4 \mathrm{kcal} \mathrm{mol}^{-1}$ for $2_{\mathrm{NO} 2}$ to $\Delta \mathrm{G}^{\ddagger}=$ $21.1 \mathrm{kcal} \mathrm{mol}^{-1}$ for $2_{\mathrm{H}}$ and hence the computational values of Figure 8 are in reasonable agreement with experiment. A comparison of the experimental rate with respect to 2 y, i.e. $\ln \left(k_{Y} / k_{H}\right)$, versus the computationally calculated change in free energy of activation change $\left(\delta \Delta G^{\ddagger}\right)$, namely between the values for $\mathbf{2}_{\mathrm{Y}}$ and $\mathbf{2}_{\mathrm{H}}$ for the hydrogen atom abstraction barriers is given in Figure 9.

Our calculated free energies of activation of hydrogen atom abstraction from toluene by these complexes (data from Figure 7) are on average about $3 \mathrm{kcal} \mathrm{mol}^{-1}$ underestimated, but as can be seen from the fit of the experimental versus computational free energies in Figure 9, the trend is the same. Note that the line fitted through the set of data has an intercept of almost zero. Therefore, the computational method appears to give a systematic error with respect to experiment with a slope that passes through the origin. A similar deviation between experimental and computational free energies of activation of substrate sulfoxidation by an iron(IV)-oxo complex was reported before with our computational methods and procedures. ${ }^{[31]}$ The most likely reason for the overestimated free energies of activation comes from an overestimation of the entropy contribution. It was shown that DFT calculations on gas-phase models overestimate the entropy by as much as $50 \%$ due to the lack of a solvent cage around the cluster that reduces the entropic contributions due to vibrations and rotations significantly. ${ }^{[31 \mathrm{c}]}$

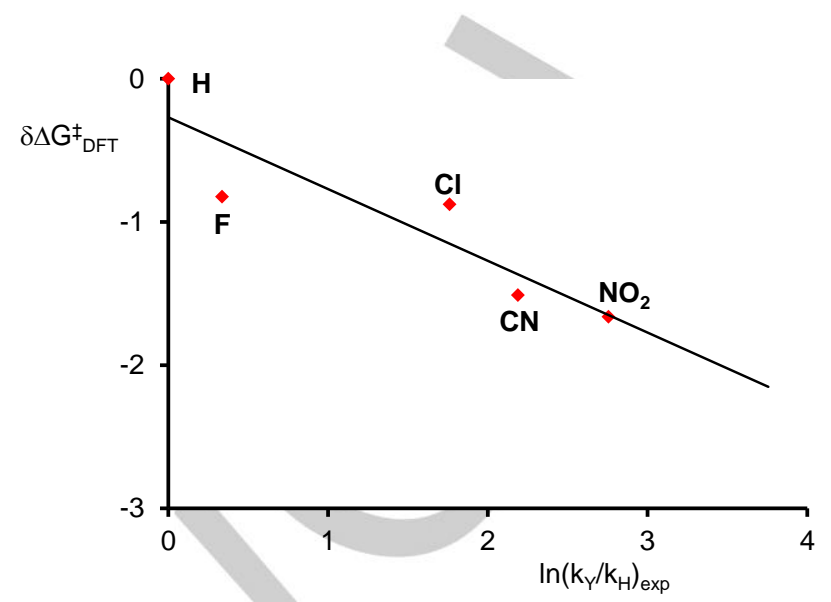

Figure 9. Correlation between the experimental and computational free energy of activation change of HAT from toluene by ${ }^{2}{ }^{2} \mathrm{Y}(\mathrm{Y}=\mathrm{H}, \mathrm{F}, \mathrm{Cl}, \mathrm{CN}$, $\mathrm{NO}_{2}$ ). Free energies are in $\mathrm{kcal} \mathrm{mol}^{-1}$, Wertz corrected and represent $\delta \Delta \mathrm{G}^{\ddagger}=$ $\Delta \mathrm{G}_{\mathrm{Y}}^{\ddagger}-\Delta \mathrm{G}_{\mathrm{H}}^{\ddagger}$.

Overall, the computational results follow the experimental results nicely and show an equatorial ligand effect on the hydrogen atom abstraction from toluene by $\left[\mathrm{Fe}^{\mathrm{V}}(\mathrm{O})(\mathrm{Y}-\mathrm{bTAML})\right]^{-}$ complexes. As such the trends are reproducible and DFT gives a small but systematic error here. To understand the origin of the reactivity trends seen from the experimental and computational studies, we analyzed the thermodynamics and electronic changes along the reaction mechanism in detail to find out how the reactivity is affected by the equatorial ligand perturbations.

First, we looked at the bond breaking and bond forming processes in the hydrogen atom abstraction, which is explained in detail in Figure 10. These valence bond (VB) approaches as shown in Figure 10 have been used by us and others before to rationalize transition states and hence rate constants of reaction processes. ${ }^{[32,33]}$ For instance, we predicted correlations between intrinsic chemical properties, such as electron affinities or bond dissociation energies, as rate-determining in a reaction mechanism. ${ }^{[32]}$ As mentioned above ${ }^{2}{ }_{2} \gamma$ has the metal in oxidation state iron $(\mathrm{V})$ and molecular orbital occupation of $\pi_{\mathrm{xz}}{ }^{2}$ $\pi_{y z}{ }^{2} \pi^{*}{ }_{x y}{ }^{2} \pi_{x z}^{*}{ }^{1} \pi_{y z}^{*}{ }^{0}$. Technically, the pair of $\pi_{x z} / \pi^{*} x z$ orbitals contain three electrons, which is roughly equally distributed over the iron and oxo groups, hence we draw it as a three-electron bond. Upon hydrogen atom abstraction from the substrate, the $\mathrm{C}-\mathrm{H}$ molecular orbital $\left(\sigma_{\mathrm{CH}}\right)$ of the substrate splits back into atomic orbitals $\left(2 \mathrm{p}_{\mathrm{C}}\right.$ and $\left.1 \mathrm{~s}_{\mathrm{H}}\right)$ at a cost of $\mathrm{BDE}_{\mathrm{CH}}$, i.e. the bond dissociation energy of the $\mathrm{C}-\mathrm{H}$ bond of the substrate. The $1 \mathrm{~s}_{\mathrm{H}}$ electron pairs up with a $2 p$ electron on oxygen $\left(2 p_{0}\right)$, which originates from the $\pi_{y z}^{2}$ bond that also splits into atomic orbitals with an energy $E_{\pi / \pi^{*} y z}$. The other electron from the $\pi_{y z}{ }^{2} \pi^{*} y z=0$ bond moves to iron and becomes the nonbonding $3 d_{y z}$. The pairing up of the $2 \mathrm{p}_{\mathrm{O}}$ and $1 \mathrm{~s}_{\mathrm{H}}$ electrons gives the bond dissociation energy of the $\mathrm{O}-\mathrm{H}$ bond, $\mathrm{BDE}_{\mathrm{OH}}$. As such hydrogen atom abstraction will create a radical intermediate with configuration $\left[\mathrm{Fe}^{\mathrm{IV}}(\mathrm{OH})(\mathrm{Y}\right.$ bTAML)] with a nearby tolyl radical. 


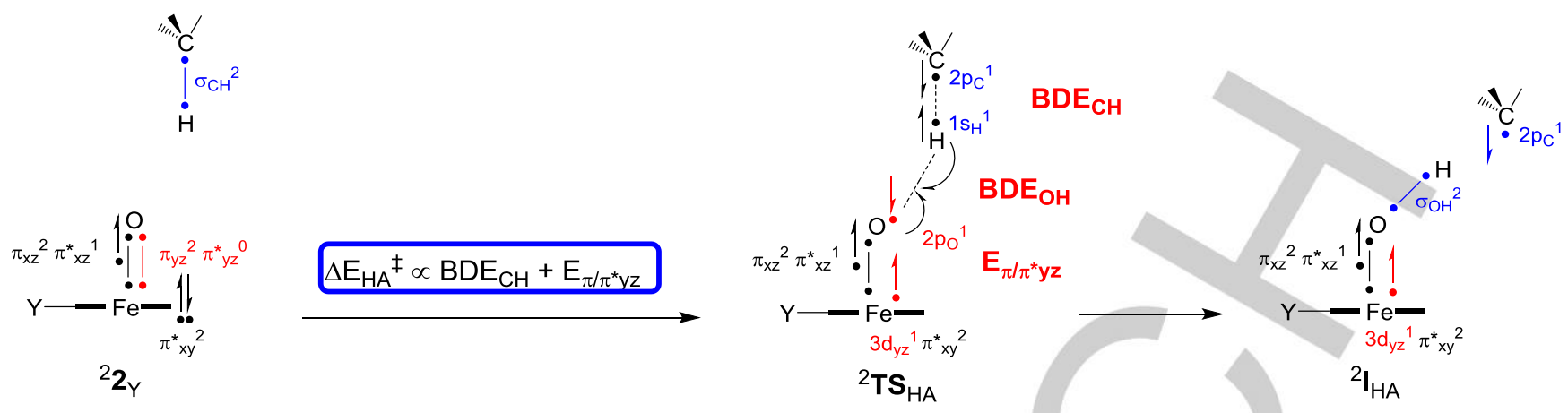

Figure 10. Valence bond description for the hydrogen atom abstraction barrier. Dots represent electrons and a line in between two dots is a chemical bond with two electrons.

The iron(IV)-hydroxo will be in the triplet spin and the tolyl radical will be down-spin. Indeed, group spin densities (Supporting Information) give all hydrogen atom transition states and radical intermediates a down-spin electron on the substrate (negative spin density), whereas approximately a spin of 2 is seen on the $\mathrm{FeOH}$ moiety. Based on the VB analysis from Figure 10, we predict the hydrogen atom abstraction barrier to correlate with $\mathrm{BDE}_{\mathrm{CH}}$ of the substrate and the $\mathrm{E}_{\pi / \pi^{*} \mathrm{yz}}$ value of the oxidant.

Technically, the $\mathrm{BDE}_{\mathrm{OH}}$ of the oxidant represents the energy to form the $\mathrm{O}-\mathrm{H}$ bond in the iron(IV)-hydroxo complex with respect to the iron(V)-oxo and a hydrogen atom. Therefore, the $\mathrm{BDE}_{\mathrm{OH}}$ value contains the energy to form the $\sigma_{\mathrm{OH}}$ orbital between the $\mathrm{O}$ and $\mathrm{H}$ atoms. In addition, the $\mathrm{BDE}_{\mathrm{OH}}$ also includes the electronic changes between the iron(V)-oxo and iron(IV)-hydroxo complexes and hence contains the value for $E_{\pi / \pi^{*} y z}$ for the splitting of the $\pi_{\mathrm{yz}} / \pi_{\mathrm{yz}}^{*}$ molecular orbitals into atomic orbitals. Since, the hydrogen atom abstraction represents the breaking of the $\mathrm{C}-\mathrm{H}$ bond (or $\sigma_{\mathrm{CH}}$ orbital) and the formation of the $\mathrm{O}-\mathrm{H}$ bond (or the $\sigma_{\mathrm{OH}}$ orbital). This implies that the hydrogen atom abstraction barrier should correlate with $\mathrm{BDE}_{\mathrm{OH}}$ as well. Indeed, the experimental trend reported in Figure $5 \mathrm{a}$ confirms a correlation between $\mathrm{BDE}_{\mathrm{OH}}$ and the rate constant for hydrogen atom abstraction. Similar trends were obtained from the computations (Supporting Information Figure S18 and S20).

Using VB curve crossing diagrams, Shaik et $\mathrm{al}^{[33]}$ showed that the barrier height for hydrogen atom abstraction is correlated to the excitation energy between the reactant and product wave functions in the geometry of the reactants. Therefore, we estimated the $E_{\pi / \pi^{*} y z}$ energy from the orbital energy levels in the reactant structures. The estimated $E_{\pi / \pi^{*} y z}$ values from the orbital energy levels of the reactant complexes give an increasing trend with the change in substituent $Y$ from electron-withdrawing, see Figure 11.

As can be seen from Figure 11 the $\pi_{y z}$ molecular orbital contains $\pi$-contributions from the $\mathrm{Y}$-substituent. Therefore, a change in substituent should give differences in the $\pi_{\mathrm{yz}} / \pi^{*}{ }_{\mathrm{yz}}$ energy gaps. Indeed, the values for the $\pi_{y z} / \pi^{*}{ }_{y z}$ energy difference of the set of $\alpha$-orbitals for all complexes ${ }^{2}{ }^{2} \mathrm{Y}\left(\mathrm{Y}=\mathrm{H}, \mathrm{F}, \mathrm{Cl}, \mathrm{CN}, \mathrm{NO}_{2}\right)$ gives a trend with electron-withdrawing substituent ranging from 122.6 $\mathrm{kcal} \mathrm{mol}{ }^{-1}$ for $\mathrm{Y}=\mathrm{H}$ to $134.0 \mathrm{kcal} \mathrm{mol}^{-1}$ for $\mathrm{Y}=\mathrm{NO}_{2}$ (Figure 11). As the $\mathrm{BDE}_{\mathrm{OH}}$ value contains a contribution for the splitting of the $\pi_{\mathrm{yz}} / \pi_{\mathrm{yz}}^{*}$ orbitals into atomic orbitals, this means that enlarged $\mathrm{E}_{\pi / \pi^{*} y z}$ values will give larger $\mathrm{BDE}_{\mathrm{OH}}$ values and hence will result in slightly stronger $\mathrm{O}-\mathrm{H}$ bonds in the iron(IV)-hydroxo complexes. Indeed, our work shows a trend in $\mathrm{BDE}_{\mathrm{OH}}$ with changes in the substituent $Y$ from $\mathrm{Y}=\mathrm{H}$ to $\mathrm{Y}=\mathrm{NO}_{2}$

To further show the electronic changes for the reactivities of the ${ }^{2} \mathbf{2}_{\mathrm{Y}}\left(\mathrm{Y}=\mathrm{H}, \mathrm{F}, \mathrm{Cl}, \mathrm{CN} \mathrm{NO}_{2}\right)$ complexes, we display in Figure 11 the group spin densities on the FeO group, the $\mathrm{Y}$-bTAML ligand and the substrate in the hydrogen atom abstraction transition state $\left({ }^{2} \mathbf{T S}_{\mathrm{HA}}\right)$ from toluene. Thus, if the substituent-effect on the high-lying molecular orbitals is large then major changes should be seen in the unpaired spin density related to the $\pi^{*}{ }_{x z}$ molecular orbital for the series with different electron-withdrawing or donating groups on the periphery of the TAML ligand. The spin densities are very similar, but small changes are seen along the reaction series and the spin on the $\mathrm{FeO}$ group decreases from

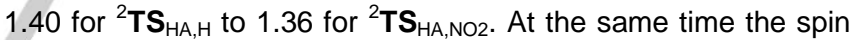
density on the ligand increases from 0.07 in ${ }^{2} \mathbf{T S}_{\mathrm{HA}, \mathrm{H}}$ to 0.11 in

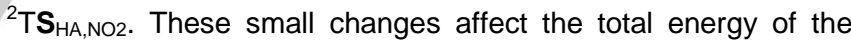
transition state and lower it slightly in energy.

Finally, we compare the hydrogen atom abstraction ability and oxygen atom transfer ability of oxidants $2 y$ with metal-oxo oxidants studied before. Thus, for P450 Cpd I models we calculated hydrogen atom abstraction barriers of 14.6 and 16.6 $\mathrm{kcal} \mathrm{mol}{ }^{-1}$ using the same methods as used in Figures 6 and 7 . As such, structures $2 y$ are considerably better oxidants than P450 Cpdl and will react faster through hydrogen atom abstraction reactions. Interestingly, we calculate a $\mathrm{BDE}_{\mathrm{OH}}$ value for P450 Cpdl that is within $1 \mathrm{kcal} \mathrm{mol}^{-1}$ of those for 2 y. However, there are differences in the electron transfer processes in the hydrogen atom abstraction and particularly in P450 an electron is shuttled in a high-lying $a_{2 u}$ porphyrin orbital. In structures $2 \gamma$ the electron is donated to a much lower lying orbital, namely the $3 d_{y z}$ orbital, and hence it will cost much less energy resulting in lower reaction barriers and higher rate constants. 


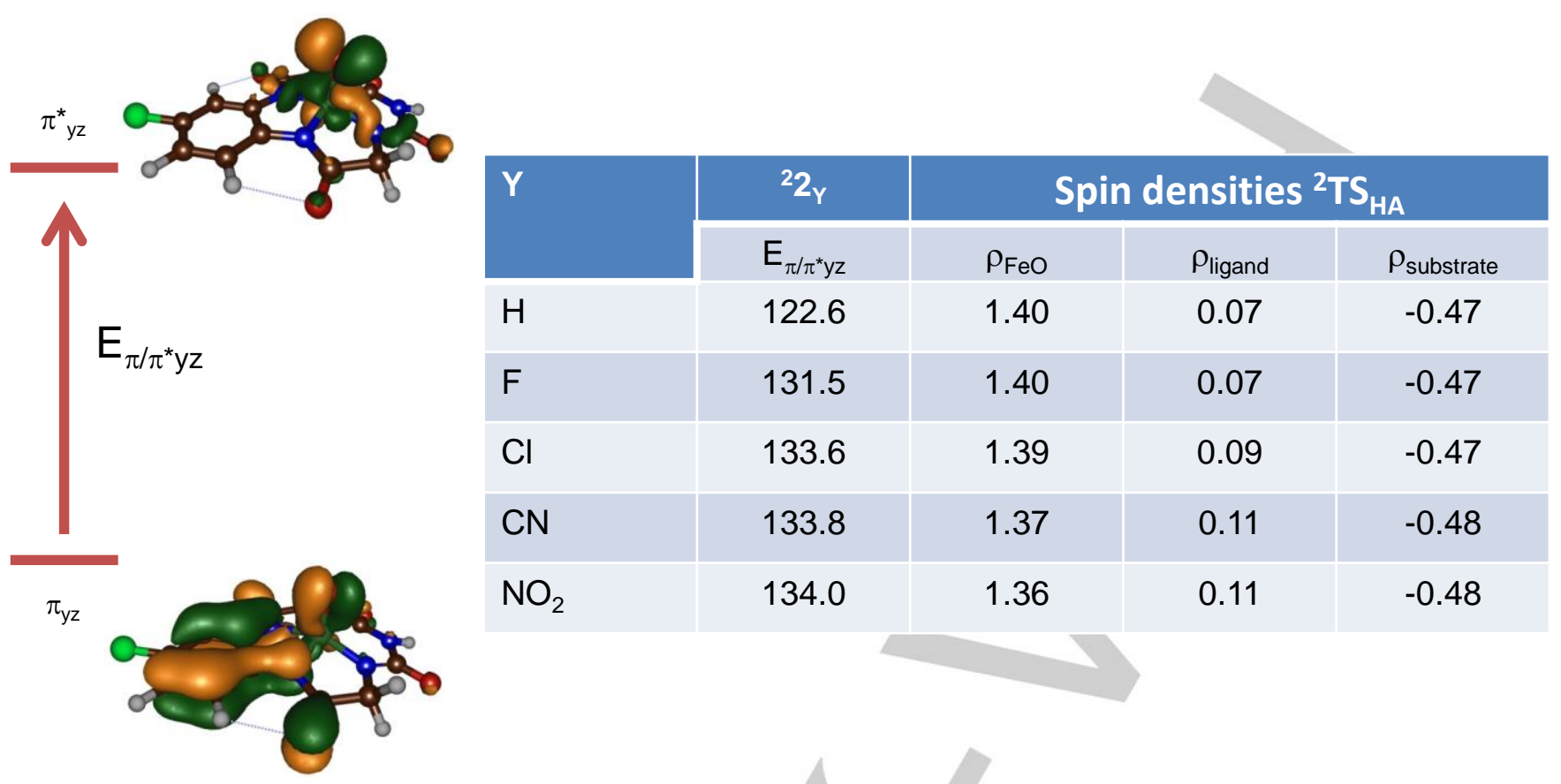

Figure 11. Electronic properties of oxidants and transition states including $\pi_{y z} / \pi^{*}$ yz energy gap of ${ }^{2} \mathbf{2} y$ (in kcal mol ${ }^{-1}$ ) and the group spin densities ( $\rho$ ) of the hydrogen atom abstraction transition states (in atomic units).

\section{Conclusions}

In conclusion, we present the synthesis, characterization and reactivity studies of a series of iron( $\mathrm{V})$-oxo complexes with biuret-modified tetraamidomacrocyclic ligand (Y-bTAML) system with $\mathrm{Y}=\mathrm{H}, \mathrm{F}, \mathrm{Cl}, \mathrm{CN}$ and $\mathrm{NO}_{2}$. These structures were characterized with UV-Visible absorption, mass spectrometry and EPR spectroscopy. The EPR spectra of the complexes are very similar and, therefore, all complexes have the same electronic ground state in a doublet spin state. However, there are dramatic changes in the UV-Vis spectra that implicate electronic changes due to equatorial ligand perturbation. Subsequently, the reactivity patterns were investigated and it is found that the rate constants correlate with the $\mathrm{BDE}_{\mathrm{OH}}$ of the oxidant. A series of computational studies were performed and establish that these changes are due the breaking of the $\pi_{\mathrm{yz}} / \pi^{*}{ }_{\mathrm{yz}}$ couple of orbitals and the formation of an iron(IV)-hydroxo bond. Overall, these oxidants are versatile systems that react faster than enzymatic analogues for substrate hydroxylation and epoxidation. Iron(V)-oxo complexes show distinct reactivity patterns from iron(IV)-oxo intermediates, whereby the rate constant of substrate activation (HAT or OAT) is dependent on equatorial ligand substitution of the biuret scaffold. As such these complexes show more versatility than traditional heme and nonheme complexes in equatorial ligand activity.

\section{Experimental Section}

Materials. $\left(\mathrm{Et}_{4} \mathrm{~N}\right)_{2}\left[\mathrm{Fe}^{\prime \prime \prime}(\mathrm{Cl})(\mathrm{Y}-\mathrm{bTAML})\right]$ or $\mathbf{1}_{\mathrm{Y}}$ was synthesized as described previously. ${ }^{[3]}$ Aqueous sodium hypochlorite (reagent grade,
Aldrich, available chlorine $4.00-4.99 \%$ ) was used as received and quantified by iodometry. Acetonitrile (LCMS grade, Aldrich) was used after passing the solution through an activated neutral alumina column and then dried. ${ }^{[35]}$ All substrates were purchased from Sigma-Aldrich as 99.8\% pure and passed through activated neutral alumina and distilled prior to use. All reactions were carried out in a glovebox in an argon environment, unless otherwise specified. Deionized water was used to make the sodium hypochlorite stock solutions for the reaction and kinetic runs.

Instrumentation. UV-vis spectral studies were carried out using an Agilent diode array 8453 spectrophotometer attached to a Peltier temperature controller. The $\mathrm{X}$-band electron paramagnetic resonance (EPR) spectrum was recorded on a Bruker EMX X-band spectrometer operating at a field modulation of $100 \mathrm{kHz}$ with a modulation amplitude of $7 \mathrm{G}$ and microwave radiation power of $10 \mathrm{~mW}$ at $90 \mathrm{~K}$, unless otherwise specified.

Gas chromatography (GC) studies were performed on a PerkinElmer Arnel Clarus 500 instrument equipped with a hydrogen flame ionization detector and HP-5 $(30 \mathrm{~m} \times 0.32 \mathrm{~mm} \times 0.25 \mu \mathrm{m})$ column. Helium was used as the carrier gas at a flow rate of $30 \mathrm{~mL} \mathrm{~min}^{-1}$. GC-MS analysis was performed on an Agilent 5977A mass-selective detector interfaced with an Agilent 7890B GC in similar conditions using a HP-5-Ms capillary column $(30 \mathrm{~m} \times 0.32 \mathrm{~mm} \times 0.25 \mu \mathrm{m})$.

Synthesis of high-valent iron(V)-oxo species. A $0.45 \mathrm{mM}$ solution of $\left[\mathrm{Fe}^{\text {III }}(\mathrm{Cl})(\mathrm{Y}-\mathrm{bTAML})\right]^{2-}\left(\mathbf{1}_{\mathrm{Y}}\right)$ reacted to form $\mathbf{2}_{\mathrm{Y}}$ through the addition of 1.2 equivalents of sodium hypochlorite $(\mathrm{NaOCl})$ in acetonitrile. ${ }^{[14,16,17,33]}$ Quantitative conversion of $\mathbf{1}_{Y}$ to $\mathbf{2}_{Y}$ was confirmed with UV-Vis spectroscopy. The substrate was added through a gas-tight microsyringe under an argon atmosphere after the formation of $2 y$ was complete and the reaction was monitored by UV-Vis spectroscopy. The change in adsorption was plotted versus the concentration of substrate and enabled us to determine the second-order rate constants of the reaction. The kinetics for the reactions of $2 y$ with toluene and cyclooctene were 
monitored using a $1 \mathrm{~cm}$ quartz cell at $395 \mathrm{~nm}$ in a thermostat bath at 30.0 $\pm 0.5^{\circ} \mathrm{C}$. All the kinetic experiments were carried out in a degassed acetonitrile solvent. The pseudo first-order rate constants $k_{\text {obs }}$ were obtained from nonlinear curve fitting and the resulting values correlated with substrate concentration to afford the second-order rate constants $k_{2}{ }^{[35]}$

The formal redox potentials $\left(E^{0 \prime}\right)$ for the $\mathrm{Fe}^{\mathrm{V} / \mathrm{IV}}$ redox couple for all the complexes were determined by cyclic voltammetry (CV) and square wave voltammetry (SQWV) in water using $\mathrm{CH}$ Instruments, Austin, TX (Model $\mathrm{CHI}$ 760D) as reported elsewhere. ${ }^{[17]}$ The $\mathrm{pK}_{\mathrm{a}}$ value of the iron(IV)-oxo was determined by monitoring the increase in absorbance at $950 \mathrm{~nm}$ due to formation of $\mu$-oxo- $\mathrm{Fe}_{2}$ dimer upon successive addition of acid in water according to the equilibrium reaction given in $\mathrm{Eq} 2$ (Supporting Information Figure S1, Table S1). ${ }^{[15]} \mathrm{BDE}_{\mathrm{OH}}$ values for all complexes were determined with Eq 1 above using the measured redox potentials and $\mathrm{pK}_{\mathrm{a}}$ values.

$$
2 \mathrm{Fe}^{\mathrm{IV}}(\mathrm{O})^{2-}+2 \mathrm{H}^{+} \rightleftharpoons 2 \mathrm{Fe}^{\mathrm{IV}}(\mathrm{OH})^{1-} \stackrel{-\mathrm{H}_{2} \mathrm{O}}{\longrightarrow}\left[\mathrm{Fe}^{\mathrm{IV}}{ }_{2} \mathrm{O}\right]^{2-}+\mathrm{H}_{2} \mathrm{O}
$$

Computation. To support the experiments a series of density functional theory (DFT) calculations on the structure, properties and reactivities of $2_{Y}, \mathrm{Y}=\mathrm{H}, \mathrm{F}, \mathrm{Cl}, \mathrm{CN}$ and $\mathrm{NO}_{2}$ were performed. We calculated the general reactivity landscape of substrate activation and the electronic structure of intermediates and transition states on all low-lying spin states with one of the oxidants, namely for $\mathrm{Y}=\mathrm{Cl}$. For all other systems the reactants were only calculated in the doublet and quartet spin states and the reaction mechanisms with substrates only focused on the rate-determining reaction step, namely $\mathrm{C}-\mathrm{O}$ bond formation for the reaction of $2 y$ with cyclooctene and hydrogen atom abstraction of its reaction with toluene. During the course of our studies we identified several substrate binding orientations and consequently, several orientations for each transition state. In order to determine a reactivity trend, we optimized all structures in the same orientation, which in all cases was the lowest energy structure.

We tested a range of density functional theory methods (see Supporting Information), but as the free energies of activation calculated with the unrestricted B3LYP ${ }^{[37]}$ method were closest to experiment we continued with this method only. Geometries were optimized without constraints and confirmed as local minima through a frequency analysis at B3LYP/BS1, whereby the BS1 basis set contains LANL2DZ with core potential on iron and $6-31 \mathrm{G}^{*}$ on the rest of the atoms. ${ }^{\left[{ }^{38]}\right.}$ All calculations were run with a solvent model (SMD) with a dielectric constant mimicking acetonitrile. To improve the energies, a single point calculation with a larger basis set (BS2) was performed, which includes a $6-311+\mathrm{G}^{*}$ basis set on all atoms and LACV3P+ (with core potential) on iron. Geometry optimizations, frequencies, geometry scans and intrinsic reaction coordinate scans were all run in Gaussian-09. ${ }^{[39]}$ To confirm the nature of the transition states a frequency analysis was performed followed by an intrinsic reaction coordinate scan to established it to connect to the assigned reactants and products. For an analogous set of chemical systems, we did extensive benchmarking with a range of density functional theory methods and basis sets, and the methods used here reproduced experimental enthalpy of activations and kinetic isotope effects excellently. ${ }^{[31,40]}$ To confirm that the trends are correct a number of calculations were repeated with the OPBE density functional method (see Supporting Information). ${ }^{[41]}$ These data confirmed the results obtained with B3LYP. Free energies are reported at $298 \mathrm{~K}$ and include zero-point, entropic, solvent and thermal corrections. Entropies were scaled as reported previously. ${ }^{[31]}$

To understand the differences of the physical properties of the various oxidants, we calculated adiabatic electron affinities (EA) of all iron(V)-oxo species as the adiabatic energy difference of the oxidant and the one- electron reduced complexes. $\mathrm{O}-\mathrm{H}$ bond dissociation energies $\left(\mathrm{BDE}_{\mathrm{OH}}\right)$ of the iron(IV)-hydroxo complexes were also calculated on both spin states from the difference in energy of the iron(IV)-hydroxo complex and the sum of the iron(V)-oxo complex and a hydrogen atom. Subsequently, correlations of the natural logarithm of the rate constant (or free energy of activation) with either $\mathrm{EA}$ or $\mathrm{BDE}_{\mathrm{OH}}$ were sought.

\section{Acknowledgements}

FGCR thanks the Conacyt Mexico for a studentship. SSG acknowledges SERB, New Delhi (Grant no EMR/2014/00016), and IISER-Kolkata ("Start-up Grant") for funding.

Keywords: biomimetic models $•$ hydroxylation $\bullet$ epoxidation $•$ enzyme models $\bullet$ inorganic reaction mechanisms

[1] K. Ray, F. F. Pfaff, B. Wang, W. Nam, J. Am. Chem. Soc. 2014, 136 13942-13958

[2] a) M. Sono, M. P. Roach, E. D. Coulter, J. H. Dawson, Chem. Rev. 1996, 96, 2841-2888; b) B. Meunier, S. P. de Visser, S. Shaik, Chem. Rev. 2004, 104, 3947-3980; c) I. G. Denisov, T. M. Makris, S. G. Sligar, I. Schlichting, Chem. Rev. 2005, 105, 2253-2277; d) Cytochrome P450: Structure, Mechanism and Biochemistry (Ed. P. R. Ortiz de Montellano), $3^{\text {rd }}$ ed., Kluwer Academic/Plenum Publishers, New York, 2005; e) P. R. Ortiz de Montellano, Chem. Rev. 2010, 110, 932-948; f) G. Grogan, Curr. Opin. Chem. Biol. 2011, 15, 241-248; g) R. Fasan, ACS Catal. 2012, 2, 647-666; h) T. L. Poulos, Chem. Rev. 2014, 114, 3919-3962; i) X. Huang, J. T. Groves, Chem. Rev. 2018, 118, $2491-$ 2553

[3] a) E. I. Solomon, T. C. Brunold, M. I. Davis, J. N. Kemsley, S. K. Lee, N. Lehnert, F. Neese, A. J. Skulan, Y. S. Yang, J. Zhou, Chem. Rev. 2000 , 100, 235-349; b) M. Costas, M. P. Mehn, M. P. Jensen, L. Que Jr., Chem. Rev. 2004, 104, 939-986; c) M. M. Abu-Omar, A. Loaiza, N. Hontzeas, Chem. Rev. 2005, 105, 2227-2252; d) P. C. A. Bruijnincx, G. van Koten, R. J. M. Klein Gebbink, Chem. Soc. Rev. 2008, 37, 27162744; e) A. R. McDonald, L. Que Jr, Coord. Chem. Rev. 2013, 257, 414-428; f) W. Nam, Y.-M. Lee, S. Fukuzumi, Acc. Chem. Res. 2014 $47,1146-1154$

[4] a) R. Davydov, R. Perera, S. Jin, T.-C. Yang, T. A. Bryson, M. Sono, J. H. Dawson, B. M. Hoffman, J. Am. Chem. Soc. 2005, 127, 1403-1414; b) J. Rittle, M. T. Green, Science 2010, 330, 933-937.

[5] a) F. Ogliaro, N. Harris, S. Cohen, M. Filatov, S. P. de Visser, S. Shaik, J. Am. Chem. Soc. 2000, 122, 8977-8989; b) T. Kamachi, K. A Yoshizawa, J. Am. Chem. Soc. 2003, 125, 4652-4661; c) C. M. Bathelt, J. Zurek, A. J. Mulholland, J. N. Harvey, J. Am. Chem. Soc. 2005, 127 12900-12908; d) D. Li, Y. Wang, K. Han, Coord. Chem. Rev. 2012, 256, 1137-1150.

[6] a) D. A. Proshlyakov, T. F. Henshaw, G. R. Monterosso, M. J. Ryle, R P. Hausinger, J. Am. Chem. Soc. 2004, 126, 1022-1023; b) J. M. Bollinger Jr, J. C. Price, L. M. Hoffart, E. W. Barr, C. Krebs, Eur. J. Inorg. Chem. 2005, 4245-4254.

[7] a) M. Atanasov, P. Comba, S. Hausberg, B. Martin, Coord. Chem. Rev. 2009, 253, 2306-2314; b) M. Costas, Coord. Chem. Rev. 2011, 255, 2912-2932; c) C. V. Sastri, J. Lee, K. Oh, Y. J. Lee, J. Lee, T. A. Jackson, K. Ray, H. Hirao, W. Shin, J. A. Halfen, J. Kim, L. Que Jr., S. Shaik, W. Nam, Proc. Natl. Acad. Sci. USA 2007, 104, 19181-19186; d) C. Buron, K. Sénéchal-David, R. Ricoux, J.-P. Le Caër, V. Guérineau, P. Méjanelle, R. Guillot, C. Herrero, J.-P. Mahy, F. Banse, Chem. Eur. J. 2015, 21, 12188-12193; e) X. Engelmann, I. MontePérez, K. Ray, Angew. Chem. Int. Ed. 2016, 55, 7632-7649.

[8] See, e.g., a) I. Prat, L. Gómez, M. Canta, X. Ribas, M. Costas, Chem. Eur. J. 2013, 19, 1908-1913; b) M. G. Quesne, D. Senthilnathan, D Singh, D. Kumar, P. Maldivi, A. B. Sorokin, S. P. de Visser, ACS Catal. 2016, 6, 2230-2243; c) P. Barman, A. S. Faponle, A. K. Vardhaman, D. Angelone, A.-M. Löhr, W. R. Browne, P. Comba, C. V. Sastri, S. P. de Visser, Inorg. Chem. 2016, 55, 10170-10181; d) J. Annaraj, J. Cho, Y.- 
M. Lee, S. Y. Kim, R. Latifi, S. P. de Visser, W. Nam, Angew. Chem. Int Ed. 2009, 48, 4150-4153; e) A. Takahashi, D. Yamaki, K. Ikemura, T. Kurahashi, T. Ogura, M. Hada, H. Fujii, Inorg. Chem. 2012, 51, 72967305; f) T. A. Jackson, J.-U. Rohde, M. S. Seo, C. V. Sastri, R. DeHont A. Stubna, T. Ohta, T. Kitagawa, E. Münck, W. Nam, L. Que Jr, J. Am. Chem. Soc. 2008, 130, 12394-12407; g) D. Janardanan, D. Usharani, S. Shaik, Angew. Chem. Int. Ed. 2012, 51, 4421-4425; h) M. E. Crestoni, S. Fornarini, F. Lanucara, Chem. Eur. J. 2009, 15, 78637866; i) H. Hirao, L. Que Jr., W. Nam, S. Shaik, Chem. Eur. J. 2008, 14 1740-1756; j) D. Balcells, C. Raynaud, R. H. Crabtree, O. Eisenstein, Inorg. Chem. 2008, 47, 10090-10099; k) H. Suzuki, K. Inabe, Y Shirakawa, N. Umezawa, N. Kato, T. Higuchi, Inorg. Chem. 2017, 56 4245-4248; I) D. P. de Sousa, C. J. Miller, Y. Chang, T. D. Waite, C. J. McKenzie, Inorg. Chem. 2017, 56, 14936-14947.

[9] S. Shaik, D. Kumar, S. P. de Visser, A. Altun, W. Thiel, Chem. Rev. 2005, 105, 2279-2328.

[10] A. S. Borovik, Acc. Chem. Res. 2005, 38, 54-61.

[11] D. Usharani, D. Janardanan, C. Li, S. Shaik, Acc. Chem. Res. 2013, 46, 471-482.

[12] R. Latifi, M. A. Sainna, E. V. Rybak-Akimova, S. P. de Visser, Chem Eur. J. 2013, 19, 4058-4068.

[13] a) T. D. H. Bugg, S. Ramaswamy, Curr. Opin. Chem. Biol. 2008, 12, 134-140; b) E. G. Kovaleva, M. B. Neibergall, S. Chakrabarty, J. D. Lipscomb, Acc. Chem. Res. 2007, 40, 475-483; c) A. Bassan, M. R. A Blomberg, P. E. M. Siegbahn, J. Biol. Inorg. Chem. 2004, 9, 439-452 d) A. Bassan, M. R. A. Blomberg, T. Borowski, P. E. M. Siegbahn, J. Phys. Chem. B 2004, 108, 13031-13041.

[14] a) S. Kundu, J. Van Kirk Thompson, A. D. Ryabov, T. J. Collins, J. Am. Chem. Soc. 2011, 133, 18546-18549; b) R. Fan, J. Serrano-Plana, W. N. Oloo, A. Draksharapu, E. A. Delgado-Pinar, A. Company, V. MartinDiaconescu, M. Borrell, J. Lloret-Fillol, E. García-Espańa, Y. Guo, E. L. Bominaar, L. Que, M. Costas, E. Münck, J. Am. Chem. Soc. 2018, 140, 3916-3928.

[15] M. Ghosh, K. K. Singh, C. Panda, A. Weitz, M. P. Hendrich, T. J. Collins, B. B. Dhar, S. S. Gupta, J. Am. Chem. Soc. 2014, 136, 9524 9527.

[16] S. Pattanayak, A. J. Jasniewski, A. Rana, A. Draksharapu, K. K. Singh, A. Weitz, M. Hendrich, L. Que Jr, A. Dey, S. S. Gupta, Inorg. Chem. 2017, 56, 6352-6361.

[17] S. Pattanayak, R. D. Chowdhury, B. Garai, K. K. Singh, A. Paul, B. B. Dhar, S. S. Gupta, Chem. Eur. J. 2017, 23, 3414-3424.

[18] M. Ghosh, S. Pattanayak, B. B. Dhar, K. K. Singh, C. Panda, S. S. Gupta, Inorg. Chem. 2017, 56, 10852-10860.

[19] C. Hansch, A. Leo, R. W. Taft, Chem. Rev. 1991, 91, 165-195.

[20] K. K. Singh, M. K. Tiwari, M. Ghosh, C. Panda, A. Weitz, M. P. Hendrich, B. B. Dhar, K. Vanka, S. S. Gupta, Inorg. Chem. 2015, 54 1535-1542.

[21] K. K. Singh, M. K. Tiwari, B. B. Dhar, K. Vanka, S. S. Gupta, Inorg Chem. 2015, 54, 6112-6121.

[22] J. J. Warren, T. A. Tronic, J. M. Mayer, Chem. Rev. 2010, 110, 69617001.

[23] a) F. G. Bordwell, J.-P. Cheng, G.-Z. Ji, A. V. Satish, X. Zhang, J. Am. Chem. Soc. 1991, 113, 9790-9795; b) F. G. Bordwell, M. J. Bausch, J. Am. Chem. Soc. 1986, 108, 1979-1985.

[24] a) J. M. Mayer, Acc. Chem. Res. 1998, 31, 441-450; b) K. L. Stone, A. S. Borovik, Curr. Opin. Chem. Biol. 2009, 13, 114-118.

[25] a) D. Kumar, B. Karamzadeh, G. N. Sastry, S. P. de Visser, J. Am. Chem. Soc. 2010, 132, 7656-7667; b) D. Kumar, G. N. Sastry, S. P. de Visser, Chem. Eur. J. 2011, 17, 6196-6205.

[26] M. T. Green, J. Am. Chem. Soc. 2006, 128, 1902-1906.

[27] a) A. Ansari, A. Kaushik, G. Rajaraman, J. Am. Chem. Soc. 2013, 135, 4235-4249; b) F. Wang, W. Sun, C. Xia, Y. Wang, J. Biol. Inorg. Chem. 2017, 22, 987-998; c) B. Mondal, F. Neese, E. Bill, S. Yeh, J. Am. Chem. Soc. 2018, 140, 9531-9544; d) H.-C. Chang, B. Mondal, H. Fang, F. Neese, E. Bill, S. Ye, J. Am. Chem. Soc. 2019, 141, 2421 2434

[28] a) S. P. de Visser, Chem. Eur. J. 2006, 12, 8168-8177; b) S. P. de Visser, L. Tahsini, W. Nam, Chem. Eur. J. 2009, 15, 5577-5587.
[29] a) S. P. de Visser, D. Kumar, S. Cohen, R. Shacham, S. Shaik, J. Am Chem. Soc. 2004, 126, 8362-8363; b) S. Shaik, D. Kumar, S. P. de Visser, J. Am. Chem. Soc. 2008, 130, 10128-10140; c) F. G. Cantú Reinhard, S. Fornarini, M. E. Crestoni, S. P. de Visser, Eur. J. Inorg Chem. 2018, 1854-1865.

[30] a) S. P. de Visser, F. Ogliaro, N. Harris, S. Shaik, J. Am. Chem. Soc 2001, 123, 3037-3047; b) D. Kumar, B. Karamzadeh, G. N. Sastry, S P. de Visser, J. Am. Chem. Soc. 2010, 132, 7656-7667; c) M. A Sainna, S. Kumar, D. Kumar, S. Fornarini, M. E. Crestoni, S. P. de Visser, Chem. Sci. 2015, 6, 1516-1529.

[31] a) A. K. Vardhaman, C. V. Sastri, D. Kumar, S. P. de Visser, Chem Commun. 2011, 47, 11044-11046; b) K. A. Prokop, H. M. Neu, S. P. de Visser, D. P. Goldberg, J. Am. Chem. Soc. 2011, 133, 15874-15877; c) F. G. Cantú Reinhard, A. S. Faponle, S. P. de Visser, J. Phys. Chem. A 2016, 120, 9805-9814.

[32] a) L. Ji, A. S. Faponle, M. G. Quesne, M. A. Sainna, J. Zhang, A Franke, D. Kumar, R. van Eldik, W. Liu, S. P. de Visser, Chem. Eur. J. 2015, 21, 9083-9092; b) F. G. Cantú Reinhard, M. A. Sainna, P. Upadhyay, G. A. Balan, D. Kumar, S. Fornarini, M. E. Crestoni, S. P. de Visser, Chem. Eur. J. 2016, 22, 18608-18619; c) F. G. Cantú Reinhard, P. Barman, G. Mukherjee, J. Kumar, D. Kumar, D. Kumar, C. V. Sastri, S. P. de Visser, J. Am. Chem. Soc. 2017, 139, 18328-18338; d) A. Timmins, M. G. Quesne, T. Borowski, S. P. de Visser, ACS Catal. 2018, 8, 8685-8698.

[33] a) S. S. Shaik, J. Am. Chem. Soc. 1981, 103, 3692-3697; b) S. Shaik, Phys. Chem. Chem. Phys. 2010, 12, 8706-8720.

[34] a) C. Panda, M. Ghosh, T. Panda, R. Banerjee, S. S. Gupta, Chem. Commun. 2011, 47, 8016-8018; b) C. Panda, J. Debgupta, D. D. Díaz, K. K. Singh, S. S. Gupta, B. B. Dhar, J. Am. Chem. Soc. 2014, 136 12273-12282.

[35] Purification of Laboratory Chemicals (Eds.: W. L. F. Armarego, D. D Perrin) $4^{\text {th }}$ ed., Elsevier Science, USA, 1997.

[36] J. H. Espenson, Chemical Kinetics and Reaction Mechanisms; $2^{\text {nd }}$ ed.; McGraw-Hill, Inc.: New York, 1995.

[37] a) A. D. Becke, J. Chem. Phys. 1993, 98, 5648-5652; b) C. Lee, W Yang, R. P. Parr, Phys. Rev. B 1988, 37, 785-789.

[38] a) R. Ditchfield, W. J. Hehre, J. A. Pople, J. Chem. Phys. 1971, 54, 724-728; b) P. J. Hay, W. R. Wadt, J. Chem. Phys. 1985, 82, 270-283.

[39] Gaussian-09, Revision C.01, M. J. Frisch, G. W. Trucks, H. B. Schlegel, G. E. Scuseria, M. A. Robb, J. R. Cheeseman, G. Scalmani, V. Barone, B. Mennucci, G. A. Petersson, H. Nakatsuji, M. Caricato, X. Li, H. P. Hratchian, A. F. Izmaylov, J. Bloino, G. Zheng, J. L. Sonnenberg, M. Hada, M. Ehara, K. Toyota, R. Fukuda, J. Hasegawa, M. Ishida, T. Nakajima, Y. Honda, O. Kitao, H. Nakai, T. Vreven, J. A. Montgomery, Jr., J. E. Peralta, F. Ogliaro, M. Bearpark, J. J. Heyd, E. Brothers, K. N Kudin, V. N. Staroverov, T. Keith, R. Kobayashi, J. Normand, K. Raghavachari, A. Rendell, J. C. Burant, S. S. Iyengar, J. Tomasi, M. Cossi, N. Rega, J. M. Millam, M. Klene, J. E. Knox, J. B. Cross, V. Bakken, C. Adamo, J. Jaramillo, R. Gomperts, R. E. Stratmann, O. Yazyev, A. J. Austin, R. Cammi, C. Pomelli, J. W. Ochterski, R. L. Martin, K. Morokuma, V. G. Zakrzewski, G. A. Voth, P. Salvador, J. J. Dannenberg, S. Dapprich, A. D. Daniels, O. Farkas, J. B. Foresman, J V. Ortiz, J. Cioslowski, D. J. Fox, Gaussian, Inc., Wallingford CT, 2010.

[40] For representative recent examples, see, e.g. a) S. Kumar, A. S. Faponle, P. Barman, A. K. Vardhaman, C. V. Sastri, D. Kumar, S. P. de Visser, J. Am. Chem. Soc. 2014, 136, 17102-17115; b) M. Pickl, S Kurakin, F. G. Cantú Reinhard, P. Schmid, A. Pöcheim, C. K. Winkler, W. Kroutil, S. P. de Visser, K. Faber, ACS Catal. 2019, 9, 565-577; c) K. Cheaib, M. Q. E. Mubarak, K. Sénéchal-David, C. Herrero, R. Guillot, M. Clémancey, J.-M. Latour, S. P. de Visser, J.-P. Mahy, F. Banse, F. Avenier, Angew. Chem. Int. Ed. 2019, 58, 854-858.

[41] a) N. C. Handy, A. J. Cohen, Mol. Phys. 2001, 99, 403-412; b) W. M. Hoe, A. J. Cohen, N. C. Handy, Chem. Phys. Lett. 2001, 341, 319-328; c) P. Perdew, K. Burke, M. Ernzerhof, Phys. Rev. Lett. 1996, 77, 38653868; d) P. Perdew, K. Burke, M. Ernzerhof, Phys. Rev. Lett. 1997, 78, 1396 . 


\section{Entry for the Table of Contents}

Layout 2:

\section{FULL PAPER}

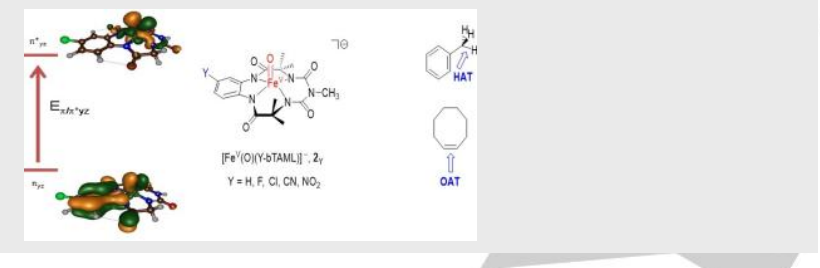

A combined experimental and computational study on the reactivity of iron(V)-oxo complexes with modified equatorial ligand substituents has been performed. The combined studies show a subtle but significant effect of the equatorial ligand perturbations on the activity and reactivity of the active species.
Santanu Pattanayak, Fabián G. Cantú Reinhard, Atanu Rana, Sayam Sen Gupta* and Sam P. de Visser *

Page No. - Page No.

The equatorial ligand effect on the properties and reactivity of iron(V)oxo intermediates 